W.

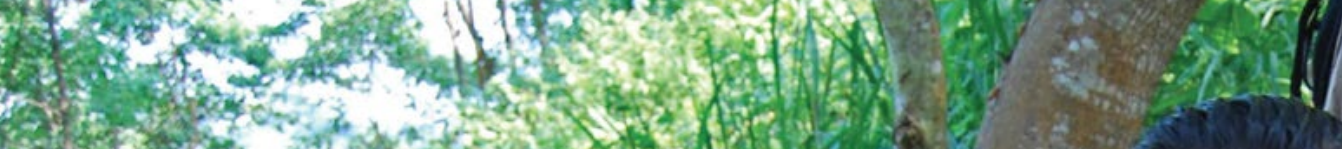

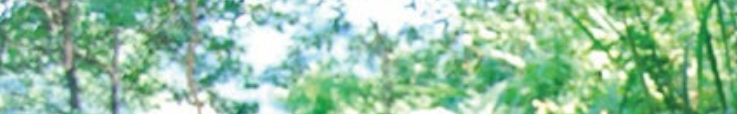

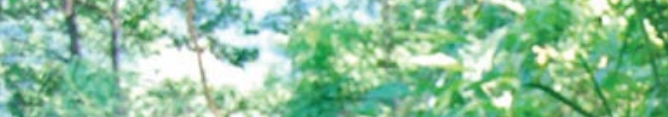

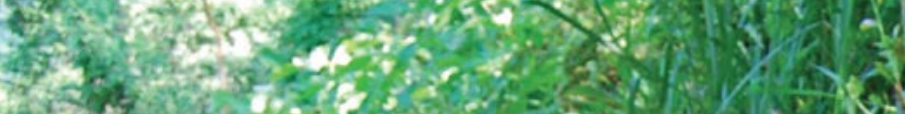

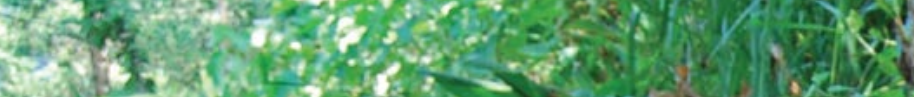
20.7.

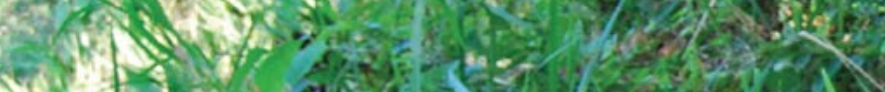

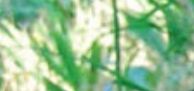
Nin

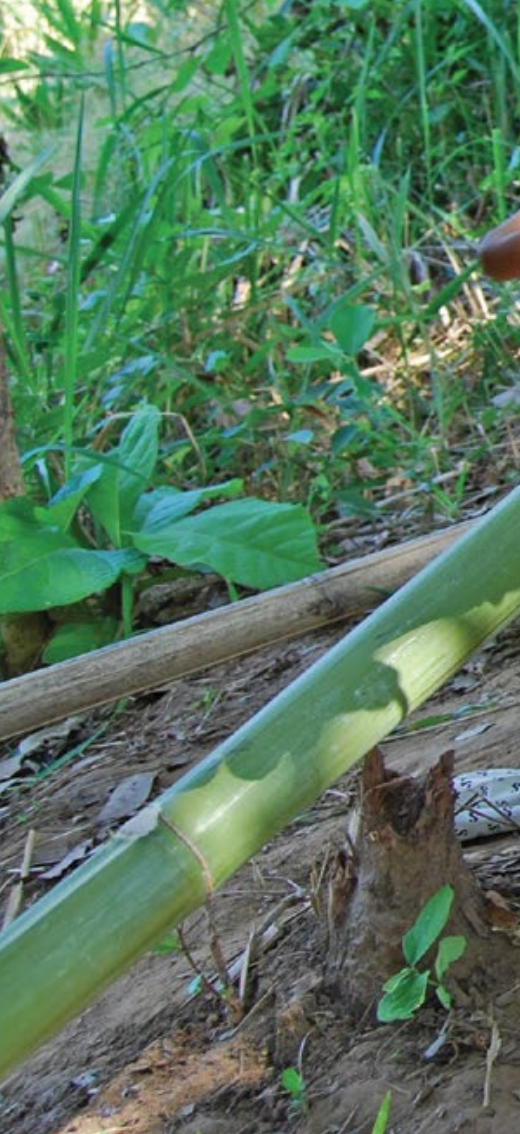

\title{
CAPÍTULO 25
}

GESTIÓN DELL USO DE

RECURSOS Y DESARROLLO

\section{Autores principales:}

Ashish Kothari y Rosie Cooney

\section{Autores de apoyo:}

Danny Hunter, Kathy MacKinnon, Eduard Müller, Fred Nelson, Krishna Oli, Sanjeeva Pandey,

Tahir Rasheed y Lubomira Vavrova

\section{CONTENIDO}

- Introducción

- Uso de recursos dentro y alrededor de las áreas protegidas

- Desarrollo y áreas protegidas

- Conclusión

- Referencias

IUCN 3 WCPA 


\section{AUTORES PRINCIPALES}

ASHISH KOTHARI es miembro fundador del grupo ambiental Kalpavriksh de India, ha trabajado como docente en el Instituto de Administración Pública de India, co-presidió el Grupo Temático y Dirección Estratégica de Gobernanza, Comunidades, Equidad y Medios de Vida en Áreas Protegidas (TILCEPA) de la Unión Internacional para la Conservación de la Naturaleza (UICN) y ayudó a fundar el Consorcio TICCA mundial.

ROSIE COONEY es presidenta de la Comisión de Política Ambiental, Económica y Social (Commission on Environmental, Economic and Social Policy, CEESP) / Grupo de Especialistas en Medios de Vida y Uso Sostenible (Sustainable Use and Livelihoods Specialist Group, SULi) de la Comisión de Supervivencia de Especies (Species Survival Commission, SSC) de la UICN y miembro de la Junta Consultiva Científica de las Naciones Unidas. Es consultora sobre políticas de biodiversidad para gobiernos, organizaciones no gubernamentales y el sector privado, y dicta conferencias en el Instituto de Estudios Ambientales, Universidad de Nueva Gales del Sur.

\section{AUTORES DE APOYO}

DANNY HUNTER es científico principal de Bioversity International y miembro de la CMAP de la UICN.

KATHY MACKINNON es presidenta adjunta de la CMAP de la UICN, fue especialista principal sobre biodiversidad en el Banco Mundial y trabajó en proyectos en África, Centro y Suramérica, Asia del Sur, Asia Oriental, Asia Central y Europa del Este.

EDUARD MÜLLER es vicepresidente de Educación y Aprendizaje, Comisión Mundial de Áreas Protegidas de la Unión Internacional para la Conservación de la Naturaleza, presidente de la Universidad para la Cooperación Internacional, Costa Rica, Catedra UNESCO de Reservas de Biosfera y Sitios patrimonio mundial Naturales y Mixtos, y Coordinador de la Alianza Global para la Profesionalización de la Gestión de las Áreas Protegidas de la CMAP.

FRED NELSON es director ejecutivo de Maliasili Initiatives, una organización que promueve el manejo sostenible de los recursos naturales y la conservación en África. Ayudó a establecer el Foro de Recursos Naturales de Tanzania.

KRISHNA PRASAD OLI trabajó con el Centro Internacional para el Desarrollo Integrado de las Montañas (International Centre for Integrated Mountain Develpment, ICIMOD) hasta su jubilación, y antes de eso con varias otras agencias, incluida la UICN en Nepal.

SANJEEVA PANDEY, como oficial del Servicio Forestal de India, ejerce como jefe principal conservador de bosques en el Departamento Forestal Himachal Pradesh de India y ha sido director del Gran Parque Nacional del Himalaya (Great Himalayan National Park, GHNP).

TAHIR RASHEED actualmente está afiliado a LEAD Pakistán como director general y ha centrado su trabajo en el uso sostenible, la investigación de políticas y adaptación al cambio climático, y en la implementación de proyectos integrados de conservación y desarrollo.

LUBOMIRA VAVROVA es consultora independiente y trabajó en Conservación Estatal de la Naturaleza de la República Eslovaca en Banská Bystrica (2002-2006) y con la Oficina del Programa para Europa Sudoriental de la UICN en Belgrado (Serbia) como oficial de proyectos de biodiversidad.

\section{AGRADECIMIENTOS}

Se agradece a Thora Amend, Richard B. Harris, Ernesto Noriega, Tatjana Puschkarsky, Mikko Rautiainen y Vivienne Solis por sus aportes a este capítulo.

\section{CITACIÓN}

Kothari, A.; Cooney, R.; Hunter, D.; MacKinnon, K.; Muller, E.; Nelson, F.; Oli, K.P.; Pandey, S.; Rasheed, T. y Vavrova, L. (2019). Gestión del uso de recursos y el desarrollo. En: G.L. Worboys, M. Lockwood, A. Kothari, S. Feary e I. Pulsford (eds.). Gobernanza y gestión de áreas protegidas, pp. 843-878. Bogotá: Editorial Universidad El Bosque y ANU Press.

\section{FOTOGRAFía DE LA PÁGINA DEL TíTULO}

Productos forestales del bosque conservado por la comunidad, parcelas de la colina Chittagong, Bangladesh

Fuente: Ashish Kothari 


\section{Introducción}

En las áreas protegidas y sus alrededores son frecuentes diferentes tipos de uso de los recursos y actividades de desarrollo. Estos tienen diversos impactos sobre los valores de conservación, están relacionados de varias maneras con la vida y los medios de subsistencia de los pueblos locales y otros sectores de la sociedad, y se abordan de distintas maneras en la gobernanza y gestión de áreas protegidas. Este capítulo brinda una visión amplia de las experiencias con el uso de recursos y el desarrollo dentro y cerca de las áreas protegidas.

La primera sección principal del capítulo trata sobre el uso de los recursos. Por lo general, se reconoce que el uso sostenible de los ecosistemas y los recursos biológicos puede desempeñar un papel importante en la gestión y la conservación de las áreas protegidas. Sin embargo, existen cuestiones complejas sobre la escala y el tipo de uso, y sobre los tipos y la fragilidad de los ecosistemas y las poblaciones de vida silvestre en que se produce dicho uso. Los enfoques convencionales que separan a las personas de las áreas protegidas u otras maneras de restringir el uso de los recursos, han comenzado a dar paso a enfoques más incluyentes. Este capítulo ayuda a entender de qué manera los modelos de uso sostenible contienen ingredientes tales como valores comunes, roles definidos, derechos y responsabilidades, mecanismos de resolución de conflictos y otras medidas que son esenciales para la gobernanza equitativa y la gestión eficaz de las áreas protegidas. El enfoque general es que la gestión de áreas protegidas es tanto una cuestión de manejar el uso humano y reconocer los vínculos de la gente con el resto de la naturaleza, como una cuestión de las características intrínsecas de los sistemas naturales. También se abordan los proyectos integrados de conservación y desarrollo (Integrated Conservation and Development Projects, ICDP), un conjunto de procesos que conectan el desarrollo y el uso de los recursos.

La segunda sección principal trata sobre los proyectos y procesos de desarrollo e infraestructura en las áreas protegidas y sus alrededores. Una faceta de esto son los proyectos que se llevan a cabo para la misma área protegida (Capítulo 24). La otra faceta son los proyectos que se llevan a cabo para otros propósitos, como la satisfacción de las necesidades y aspiraciones de las poblaciones dentro o fuera del área protegida, o de personas más alejadas, incluidas las industrias extractivas y de otro tipo, la infraestructura y la generación de energía, entre otros. Estos proyectos suelen tener un impacto negativo sobre los valores de conservación de las áreas protegidas y, por lo tanto, deben abordarse mediante respuestas apropiadas a nivel legal, social y administrativo.

\section{Uso de recursos dentro y alrededor de las áreas protegidas}

En su mayoría, las áreas protegidas de todo el mundo han sido tradicionalmente habitadas o utilizadas por humanos. Los usos residenciales, móviles o estacionales de tierras, aguas y especies silvestres dentro de dichas áreas son antiguos y están generalizados. Aunque no se cuenta con evaluaciones minuciosas a nivel mundial, las extrapolaciones basadas en estudios indicativos de diversas regiones y países citados más adelante sugieren que es probable que una gran proporción, si no la mayoría, de las áreas protegidas estén habitadas o la gente haga uso de sus recursos.

Las cifras disponibles de algunas regiones o países sugieren que la cantidad de personas que actualmente utilizan recursos dentro de las áreas protegidas es de, al menos, varias decenas de millones. Un análisis global de la situación a finales de la década de 1990 reveló que cerca del $70 \%$ de los más de treinta mil (en ese entonces) sitios en la lista de áreas protegidas de las Naciones Unidas permitía algún uso local de los recursos naturales (Pretty, 2002). En India, el 69\% de las aproximadamente doscientas cincuenta áreas protegidas encuestadas a finales de la década de 1980 estaba habitado, y el 64\% contaba con arrendamientos, concesiones o derechos comunitarios; de tres a cuatro millones de personas viven dentro de las áreas protegidas, y en las áreas adyacentes varios millones más que usan los recursos dentro de ellas (Kothari et al., 1989). Es poco probable que la situación haya cambiado significativamente desde entonces. $\mathrm{Al}$ menos cinco áreas protegidas informaron una población de más de cien mil personas al interior de sus linderos. Casi el 90\% de los 1984 parques nacionales declarados hasta 1991 en Suramérica estaban habitados o tenían cierto uso de sus recursos (Amend y Amend, 1995). En Europa, un número considerable de áreas protegidas también alberga poblaciones humanas.

Si se incluyen los "nuevos" tipos de gobernanza de las áreas protegidas (véase el Capítulo 7) que no son necesariamente parte del sistema formal, como los Territorios y Áreas Conservados por Pueblos Indígenas y Comunidades Locales (TICCA) y las Áreas Protegidas Privadas (APP), hay una proporción aun mayor de áreas que están habitadas o son utilizadas, y la cantidad de personas involucradas aumenta varias veces. No obstante, no existen cifras exactas sobre este tipo de áreas protegidas. 


\section{Estudio de caso 25.1 Ejemplo del uso de recursos dentro de áreas protegidas en Pakistán}

En Pakistán, las áreas protegidas ofrecen bienes y servicios para un gran número de personas (Ley Forestal de Pakistán de 1927, Ley de Vida Silvestre de

Pakistán de 1974; Jan, 1992). Las áreas forestales protegidas (inicialmente declaradas para mantener los recursos forestales, pero más recientemente también orientadas a la conservación de la vida silvestre) se dividen en las categorías de propiedad estatal o de propiedad privada/ comunitaria: según Jan (1992), el 66\% son bosques estatales, mientras que el $34 \%$ son propiedad de las comunidades locales o de privados. En ambas categorías se incluyen ciertos privilegios y derechos de uso.

Los bosques protegidos designados (de propiedad estatal) permiten algunos derechos y concesiones, incluidos el pastoreo, el corte de hierba y la recolección de madera seca, a menos que el Gobierno los prohíba.
Los bosques de Guzara (subsistencia) (de propiedad privada/comunitaria) se reservaron para satisfacer las necesidades legítimas de las comunidades locales, especialmente en las áreas de Malakand y Hazara en Pakistán. En estos bosques, los titulares de derechos consuetudinarios tienen derecho al 60\%-80\% de los ingresos por extracción de madera (llevada a cabo por el Departamento Forestal), a cortar árboles verdes (a través de permisos) y a la recolección de PFNM. Tanto los titulares de derechos consuetudinarios como otros residentes dentro de un radio de ocho kilómetros pueden recoger madera seca y llevar sus animales a pastar.

En la mayoría de las áreas protegidas se crean zonas de amortiguamiento principalmente con el fin de proporcionar productos de uso o valor (cultivos comerciales) para la población local. sigan estilos de vida tradicionales, lo cual abarca el uso de recursos de manera compatible con los objetivos de conservación. Estas áreas también son promovidas por sus valores turísticos, particularmente el ecoturismo. Del mismo modo, las áreas protegidas de la Categoría II (Parque nacional) pueden tener dentro de sus objetivos la inclusión de las necesidades de los pueblos indígenas y locales en términos del uso sostenible de los recursos para fines de subsistencia. Algunas veces, la Categoría IV (Áreas de manejo de hábitats/especies) dependerá de patrones tradicionales de uso de recursos (por ejemplo, pastoreo) para mantener los valores de conservación deseados, mientras que uno de los principales objetivos de la Categoría $\mathrm{V}$ (Paisaje terrestre/marino protegido) es mantener los patrones de interacción entre los humanos y el paisaje terrestre/ marino a través de prácticas tradicionales. Finalmente, el uso sostenible es el foco de las áreas protegidas de la Categoría VI (Área protegida con uso sostenible de los recursos naturales). Tales áreas cubren ahora el 32\% del área global de las categorías de áreas protegidas asignadas de la UICN (la más grande) y se ha observado que tienen niveles similares de naturalidad o influencia humana que las áreas de la Categoría II (Parque nacional) (Bertzky et al., 2012).

\section{Actitudes hacia el uso de los recursos en áreas protegidas}

\section{Una historia de exclusión: el modelo Yellowstone}

En muchas partes del mundo, el establecimiento de áreas protegidas formales siguió el "modelo Yellowstone", establecido en 1872 con la declaración del Parque Nacional Yellowstone en Estados Unidos. Este paradigma solía ser proteccionista y excluyente, con las creencias intrínsecas de que el uso humano es necesario o inherentemente perjudicial para los objetivos de conservación y que el aparato estatal es el enfoque de gobernanza más eficaz para lograr los objetivos de conservación (Neumann, 1988; Kothari et al., 1995; Adams, 2004). Desde entonces, el enfoque en Yellowstone y en muchas otras áreas protegidas ha evolucionado. Sin embargo, el enfoque excluyente sigue siendo prevalente en muchas partes del mundo y es raro que se tomen medidas para restituir los derechos consuetudinarios en los lugares de donde fueron retirados.

Con frecuencia, las áreas protegidas administradas por el Gobierno se establecen sin consultar a las comunidades que viven en ellas o utilizan sus recursos. La tenencia de la vida silvestre y los recursos suele pertenecer legalmente al Estado, lo que provoca el deterioro de los sistemas de tenencia consuetudinarios e incluso la expulsión de las comunidades de usuarios y de los residentes locales de sus áreas ancestrales -los Nativos Americanos fueron expulsados de Yosemite y de otros parques nacionales en EE.UU., los Masáis fueron expulsados de reservas ahora icónicas como Serengueti en Tanzania; lo mismo sucedió con los Batwa ("pigmeos") de Bwindi en Uganda, con los Karen de las reservas en Tailandia y con varias comunidades habitantes del bosque de las reservas de tigres en India. Los Basarwa ("bosquimanos") de Botsuana también fueron expulsados de la Reserva de Caza del Kalahari Central (de áreas que habían ocupado durante treinta mil ańos) y estos no son los únicos casos (Spence, 1999; West et al., 2006; Dowie, 2009; Lasgorceix y Kothari, 2009). Esto solo se sumó al despojo y desempoderamiento de las comunidades con propósitos de colonización e industrialización.

No obstante, en algunas regiones como Europa y partes de la cuenca amazónica, el uso de los recursos y las poblaciones locales existentes se integraron desde el principio 
en la visión y el manejo de las áreas protegidas. Algunos ejemplos de esto aparecen más adelante en este capítulo.

Las primeras leyes de caza en Sudáfrica y África Oriental estaban dirigidas principalmente a quienes ocuparon las tierras en la época colonial, cuyas acciones conducían a una reducción drástica en el número de grandes mamíferos (por ejemplo, comerciantes de marfil, trofeos de caza y cazadores deportivos) o a la eliminación de la vida silvestre en algunas áreas para los asentamientos agrícolas (Anderson y Grove, 1987). Las primeras áreas protegidas en África Oriental mantuvieron los derechos consuetudinarios de la tierra y el uso de los recursos de las comunidades locales (Nelson et al., 2007). Durante la primera mitad del siglo XX, las políticas de áreas protegidas se desplazaron hacia una postura más excluyente, lo que desincentivó la residencia y el uso de los recursos por parte de las comunidades locales. Los principales debates tuvieron lugar en el período anterior y posterior a la independencia en África Oriental, por ejemplo, en torno a la residencia de los pastores en reservas clave de vida silvestre como el Parque Nacional Amboseli en Kenia y el Parque Nacional Serengueti en Tanzania (Neumann, 1998). A menudo, este cambio hacia la exclusión era impulsado más por nociones externas sobre la necesidad de una "naturaleza prístina e inviolable" que por cualquier análisis empírico de los impactos positivos o negativos de las comunidades locales sobre la conservación (Homewood y Rodgers, 1991; Neumann, 1998); sin embargo, tal como se reconoce más adelante, esto no significa que las comunidades siempre hayan estado en armonía con su entorno natural.

En varios países donde se mantienen los privilegios locales sobre el uso de los recursos dentro de las áreas protegidas por el Estado, esto suele ser más la excepción que la regla, en particular con referencia a las áreas dentro de las categorías I, II y IV de la UICN. Nuevamente, la historia del Serengueti en Tanzania es aleccionadora. Cuando las comunidades Masáis fueron desalojadas y el Parque Nacional Serengueti fue declarado como área protegida excluyente en 1959, esto se basó en un compromiso con estas comunidades, con la exclusión de las tierras altas del Ngorongoro y la parte adyacente de las llanuras del Serengueti del parque y su inclusión en la nueva Área de Conservación de Ngorongoro (Ngorongoro Conservation Area, NCA), la cual tiene múltiples usos (Homewood y Rodgers, 1991). El NCA se estableció explícitamente -y en África Oriental, de manera excepcional- como un área de conservación administrada por el Estado con el mandato de equilibrar la conservación de la vida silvestre y el desarrollo económico local. Los derechos consuetudinarios de los Masáis a la residencia y a los usos de los recursos, prin- cipalmente a través del pastoreo tradicional del ganado, se incorporaron explícitamente en el sistema de administración y estatutos del NCA.

En 1998, en Sudáfrica, mediante el proceso de reclamación de tierras posapartheid y las negociaciones relacionadas con la autoridad del parque nacional, la comunidad Makuleke recibió la adjudicación de aproximadamente veinte mil hectáreas de tierra dentro del Parque Nacional Kruger (Reid, 2001). Sin embargo, esta reclamación solo se reconoció sobre la base de que no se permitiría un cambio de uso en las tierras de conservación, y que los Makuleke luego arrendarían sus tierras como un parque nacional contractual a Parques Nacionales de Sudáfrica. En general, los administradores de áreas protegidas en muchas partes de África siguen siendo reacios a incorporar el uso local o la cogestión en las principales áreas protegidas, particularmente en los parques nacionales (Steenkamp y Uhr, 2000).

En el subcontinente indio existe una larga historia de conservación y protección dentro de una amplia diversidad de formas, tanto por las comunidades como por los gobernantes. No obstante, en tiempos más modernos, el modelo Yellowstone se adoptó de manera uniforme para la declaración de áreas protegidas formales (Saberwal et al., 2001). La biodiversidad suele concentrarse en áreas donde la pobreza (en el sentido convencional de la palabra) tiende a ser dominante y donde el alcance de los programas de desarrollo del Gobierno suele ser limitado (Pandey y Wells, 1997). A menudo, el establecimiento de un área protegida en tales circunstancias resulta en la interrupción del uso de los recursos por parte de la comunidad. En India, entre cien mil y seiscientas mil personas fueron físicamente desalojadas y otros cientos de miles fueron privadas de sus medios de subsistencia (Wani y Kothari, 2007; Lasgorceix y Kothari, 2009).

Latinoamérica tiene una historia más heterogénea. En Costa Rica, Chile y Argentina, las áreas protegidas se establecieron relativamente temprano en su historia, especialmente bajo el concepto de "parques nacionales", en el que la mayoría de la tierra es propiedad del Estado (aunque en casos como Costa Rica, el Gobierno todavía debe a los propietarios originales el pago por la expropiación de un poco menos de la mitad de la tierra ahora incluida en las áreas protegidas) (Programa Estado de la Nación, 2006). En México, solo un pequeño porcentaje de la tierra en las áreas protegidas es propiedad del Gobierno Federal, con un alto porcentaje bajo regímenes de propiedad comunitaria o privada, lo que significa que el sistema de áreas protegidas debe negociar constantemente con los propietarios para su protección (Bezaury-Creel y Carbonell, 2009). 


\section{La evolución a partir de un enfoque de exclusión}

La última parte del siglo XX atestiguó un nuevo examen de algunos de estos enfoques para la conservación de la biodiversidad. A menudo, la planeación para la conservación emplea enfoques "de arriba hacia abajo" y de planeación central que prestan poca atención a las necesidades o aspiraciones de las comunidades locales (Hunter y Heywood, 2011). Con frecuencia, estas estrategias de "comando y control" perpetúan la pobreza, la desigualdad y las estructuras de poder que obstaculizan la realización de la conservación de la biodiversidad y las metas de bienestar sostenible desde el principio. Las comunidades indígenas y locales en países ricos en biodiversidad han estado estrechamente vinculadas a sus ambientes naturales durante milenios y tienen un conocimiento profundo de los hábitats y sus especies silvestres de plantas y animales, una relación que suele interrumpirse con los enfoques de conservación convencionales (UN, 2009). Por ejemplo, la zona marítima territorial de Costa Rica ha impedido que los pescadores en pequeńa escala y las comunidades costeras tengan acceso a la tierra y a los recursos de los que dependen (Fonseca, 2009). Cada vez más se reconoce que no es políticamente factible ni éticamente justificable negar a las comunidades locales el uso de los recursos naturales sin proporcionarles medios alternativos de subsistencia o administrar las áreas protegidas sin su empoderamiento y apoyo (McNeely et al., 1990; Wells et al., 1992; WRI et al., 1992). En algunos casos, el uso regulado de los recursos también puede proporcionar un flujo de ingresos para el manejo de áreas protegidas.

El crecimiento de las becas para propiedades comunes desde finales de la década de 1980, así como los estudios recientes, han resaltado la capacidad de la población local para gestionar de manera sostenible y eficaz los recursos naturales y los ecosistemas (Berkes, 1989; Ostrom, 1990; Hayes, 2006; Porter-Bolland et al., 2011; Nelson y Chomitz, 2011). De ninguna manera esto es universal y en varios casos también hay evidencias de insostenibilidad (Terborgh, 2004), incluidas las extinciones causadas por pueblos antiguos, pero este es un fenómeno lo suficientemente extendido como para requerir una mayor atención que la prestada por las políticas de conservación convencionales. Un factor particularmente importante es la capacidad de las comunidades para diseñar y hacer cumplir las normas que rigen el uso de los recursos, lo que destaca la necesidad de delegar derechos claros a los usuarios locales sobre los recursos dentro y alrededor de las áreas protegidas (Chhatre y Agrawal, 2009). Estos hallazgos científicos no solo han aumentado la legitimidad de más formas comunitarias para la gobernanza y gestión de las áreas protegidas, sino también han resaltado que en muchos casos las áreas protegidas de uso múltiple o las tierras indígenas pueden ser instrumentos de conservación tan efectivos como las áreas protegidas estrictas de las categorías I o II, especialmente cuando existen presiones comparables (Nelson y Chomitz, 2011). Esto no quiere decir que los pueblos indígenas y las comunidades locales estén en todas las situaciones y casos orientados a la conservación; muchos están sujetos a influencias externas e internas que afectan sus formas tradicionales o consuetudinarias, y también existen múltiples influencias y presiones para que las generaciones más jóvenes adopten estilos de vida no sostenibles. No obstante, si no hay variaciones en todos los otros factores, parece que para una conservación eficaz deben adaptarse cada vez más los enfoques participativos basados en los derechos.

Debido a estas dinámicas multifacéticas, la exclusión estricta del uso de los recursos, cuando sea necesaria y benéfica en situaciones en que dicho uso sea intrínsecamente perjudicial para las especies o ecosistemas locales (tales situaciones se tratan más adelante en este capítulo), también puede tener impactos nocivos y perjudiciales. Tales impactos incluyen: distanciar a las comunidades locales de los esfuerzos de conservación, lo que elimina cualquier incentivo para cooperar con los administradores y las regulaciones del área protegida; perder los beneficios de la conservación y la gestión del conocimiento y las prácticas tradicionales de manejo de recursos; empeorar el uso ilegal; cambiar el uso de recursos a otras áreas, con una intensificación de los impactos; aumentar el uso ilegal por parte de "extraños", al eliminar los derechos y la presencia de los custodios tradicionales; alterar las complejas redes tróficas con consecuencias imprevistas sobre las especies que son objetivo de conservación, y eliminar opciones para la financiación sostenible y necesaria de las áreas protegidas.

La eliminación de las ovejas domésticas del propuesto Parque Nacional Patagonia es un factor que inadvertidamente podría conducir a la disminución de la especie que pretende proteger; el ciervo huemul (Hippocamelus bisulcus) (Wittmer et al., 2013). se cree que la prohibición del pastoreo de búfalos en el emblemático Parque Nacional Keolodeo (Bharatpur) de India provocó cambios en el hábitat que van en detrimento de la conservación de la grulla siberiana en peligro de extinción (Vijayan, 1991). Se ha documentado que la prohibición de los incendios forestales en una reserva de tigres en el sur de India tuvo impactos ecológicos negativos que los pueblos indígenas preveían (véase el Estudio de caso 8.1 sobre incendios y la tribu Soliga). 


\section{Cambio de paradigmas: mayor inclusión y nuevos modelos para la gestión y manejo de áreas protegidas}

La misión de las áreas protegidas públicas se expande cada vez más, desde la conservación de la biodiversidad hasta la incorporación de consideraciones para mejorar el bienestar humano. El resultado es un cambio a favor de las áreas protegidas que permitan el uso sostenible de los recursos locales (Naughton-Treves et al., 2005) o formas recreativas, de investigación, educativas o comerciales del uso de recursos que beneficien a las personas y las comunidades locales. Aunque las áreas protegidas son designadas o están destinadas principalmente a la conservación de la biodiversidad, cada vez más se las considera también como impulsoras y proveedoras de beneficios sociales y económicos (Brandon et al., 1998).

En general, ahora se considera que la participación comunitaria es fundamental para alcanzar los objetivos económicos, políticos, sociales y ambientales que sustentan la conservación, mientras que la conservación excluyente se cuestiona por motivos sociales, institucionales y de sostenibilidad (Saberwal et al., 2001). Cada vez se reconocen más no solo los derechos y reclamaciones de los pueblos indígenas y las comunidades locales sobre sus tierras y recursos tradicionales, sino también los impactos negativos que el establecimiento de áreas protegidas suele tener sobre estos (West et al., 2006). Encuestas globales y análisis comparativos de estudios de casos han resaltado que los profesionales y administradores de la conservación ahora consideran la participación como uno de los factores de éxito más importantes para la gestión y el manejo (Stoll-Kleemann y Welp, 2008), aunque la participación no siempre se traduce en beneficios económicos para la población local (Galvin y Haller, 2008).

Otros se refieren a este cambio como el alejamiento del "enfoque de preservación" -tratar de aislar y mantener la biodiversidad en áreas protegidas al excluir a las comunidades indígenas y locales- hacia un enfoque más biocultural (los vínculos inextricables entre la naturaleza y la cultura), lo cual permite la actividad humana como parte del proceso y, por lo tanto, genera una estrategia de conservación mucho más exitosa- (Hunter y Heywood 2011) (véanse también los Capítulos 4 y 23). A menudo, parte de estos enfoques es mantener o habilitar diversas formas de uso de los recursos en las áreas protegidas. Por ejemplo, la Reserva Nacional Niassa en el norte de Mozambique es la más grande (42.000 kilómetros cuadrados) en el sistema de áreas protegidas de vida silvestre del país, con cerca del $80 \%$ de los elefantes en Mozambique, e incorpora el uso local consuetudinario, la residencia y la coexistencia, con una población residente de alrededor de 35.000 personas (Wikipedia, 2014; Niassa Carnivore Project, 2013).

El manejo comunitario de los recursos naturales (Community-Based Natural Resource Management, CBNRM), uno de los modelos incluyentes más comunes, representa un cambio de un enfoque centralizado a uno en el que se delega más. El CBNRM es básicamente un término general que denota una amplia gama de prácticas mediante las cuales, instituciones colectivas o grupos de personas locales, organizados formal o informalmente, manejan y utilizan sus tierras, recursos y propiedades comunales. Esto puede o no involucrar un área protegida. Una revisión reciente del impacto de los enfoques de CBNRM en África destacó algunos logros ecológicos, económicos e institucionales notables (Roe et al., 2009). No obstante, tal como señalaron muchas revisiones durante las últimas dos décadas, la CBNRM depende en última instancia de que a nivel local se delegue la autoridad y la tenencia sobre la tierra y los recursos, y esto suele verse obstaculizado por barreras político-económicas (Gibson, 1999; Nelson, 2010; de Beer, 2013).

Los proyectos integrados de conservación y desarrollo (Integrated Conservation and Development Project, ICDP) son un subconjunto de estos enfoques más incluyentes, los cuales vinculan la conservación de la biodiversidad, a menudo en o alrededor de áreas protegidas, con el desarrollo social y económico local (Wells et al., 1999). Por lo general, los ICDP se dirigen tanto al área protegida (mediante el fortalecimiento de la gestión) como a las comunidades locales (al ofrecer incentivos, como las oportunidades de desarrollo rural, a fin de reducir la presión de las actividades perjudiciales para los hábitats y los recursos naturales). Aunque muchos de los ICDP comenzaron como iniciativas pequeñas dirigidas por $\mathrm{ONG}$, despegaron realmente cuando los donantes internacionales adoptaron el concepto de vincular la conservación con el alivio de la pobreza. En la actualidad, muchas áreas protegidas participan en modelos de ICDP que varían en tamaño y alcance, desde los esfuerzos basados en el sitio hasta los programas de gran envergadura que intentan integrar la conservación con el desarrollo regional (por ejemplo, véase Cadman et al., 2010). Estos proyectos ofrecen un cóctel casi irresistible de beneficios percibidos -conservación de la biodiversidad, mayor participación de la comunidad local, distribución más equitativa de los beneficios y desarrollo económico para los pobres de las zonas rurales-. Algunos de estos proyectos han logrado éxitos notables e inspiradores, pero muchos ICDP no han cumplido sus objetivos de conservación o desarrollo (Brandon et al., 1998; Hackel, 1999; Oates, 1999; Wells et al., 1999; McShane y Wells, 2004; Alers et al., 2007). 


\section{Estudio de caso 25.2 Ecodesarrollo en el Gran Parque Nacional del Himalaya, India}

En la década de 1990, los enfoques de ICDP se introdujeron en varios lugares de India, incluido el Gran Parque Nacional del Himalaya (GHNP). El programa comenzó aquí en 1994 con un Proyecto de Extensión y Educación para la Investigación Forestal (Forestry Research Education and Extension Project, FREEP) financiado por el Banco Mundial, el cual tenía un subproyecto adicional, la Conservación de la Biodiversidad (CoB) (Pandey y Wells, 1997). Al finalizar el proyecto, los administradores del parque comenzaron programas basados en los medios de subsistencia en el área de amortiguamiento con el objetivo de establecer sistemas comunitarios alternativos para el manejo de los recursos naturales y la resolución de conflictos entre humanos y animales a través de un modo de gestión participativa (Tandon, 2002; Pandey, 2008).

Dentro de la zona de amortiguación, las mujeres pertenecientes a los hogares más pobres y más dependientes de los recursos del parque se organizaron a través de programas para el desarrollo de capacidades en Grupos de Ahorro y Crédito para Mujeres (Women's Savings and Credit Groups, WSCG). Cerca de mil mujeres en 95 WSCG recibieron actividades alternativas generadoras de ingresos: vermicompostaje, producción de aceite de albaricoque, productos de cáñamo, ecoturismo, teatro callejero y trabajo asalariado. Se están desarrollando mecanismos para que los WSCG fortalezcan el consejo de aldea (panchayat) y se vuelvan sostenibles.

El enfoque de ecodesarrollo en el GHNP también ha sido criticado por investigadores y activistas. No hubo un proceso democrático para determinar si un parque nacional, que por ley requiere la eliminación de todos los usos hu- manos, era la categoría de conservación apropiada para aplicarse aquí; no se consideró un enfoque integrado de conservación y medios de subsistencia, y la compensación es insuficiente cuando se compara con la pérdida de medios de subsistencia debido al cese de actividades como la recolección de hierbas (Baviskar, 2003; Chhatre y Saberwal, 2006). Además, si bien los usos tradicionales de los pueblos se detuvieron, el parque está sometido a un desarrollo hidroeléctrico altamente perjudicial. Así, el proceso en el GHNP refleja las contradicciones del enfoque convencional de áreas protegidas prevaleciente en India (Saberwal et al., 2001).

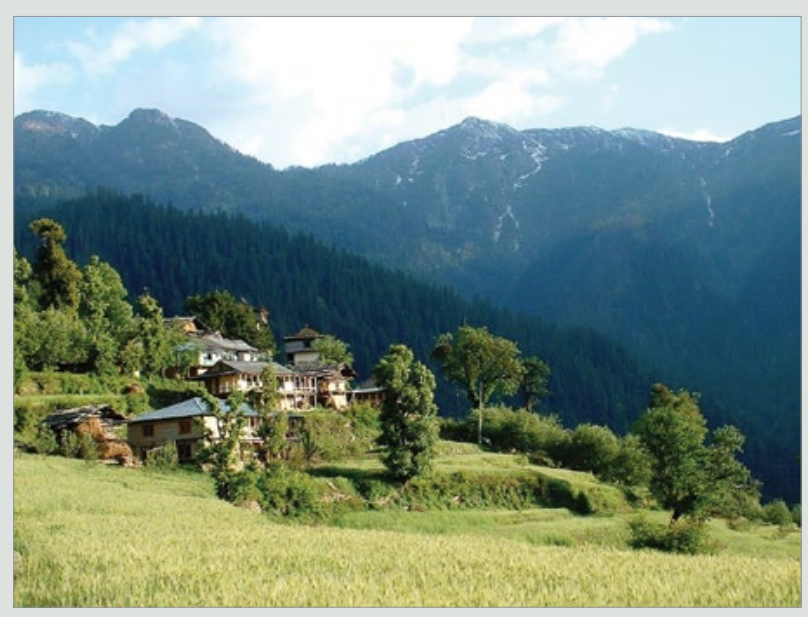

Aldea en la zona de amortiguación del Gran Parque Nacional del Himalaya, India

Fuente: Sanjeeva Pandey
Esta experiencia diversa con los ICDP se ilustra en el caso de India. En algunos sitios, los comités de ecodesarrollo empoderaron a los aldeanos con información y vías de participación, crearon grupos juveniles y de mujeres, permitieron que los aldeanos accedieran a oportunidades de medios de subsistencia adicionales y a recursos de desarrollo a través de esquemas de gobierno local (panchayat), liberaron a comunidades tribales y a otros aldeanos pobres de los prestamistas, y aumentaron en gran medida la cooperación entre las comunidades y los oficiales forestales. En la Reserva de Tigres Periyar, los recolectores de corteza de canela fueron alentados a abandonar sus actividades de caza furtiva y en su lugar a utilizar sus conocimientos forestales para guiar a los turistas. Aunque sus ingresos del turismo eran inferiores a los de la actividad ilícita, ya no estaban en conflicto con el Departamento Forestal ni en deuda con los prestamistas para pagar sus multas, y mejoraron su posición social dentro de la comunidad (Periyar Tiger Reserve, 2012). No obstante, estas ganancias no se materializaron en otros sitios; a nivel nacional, el esquema de ecodesarrollo en curso se ha caracterizado por debilidades conceptuales serias, un monitoreo inadecuado o nulo de los impactos, la falta de evaluaciones indepen- dientes y la falta de poder compartido con las comunidades locales en relación con la toma de decisiones (Das, 2007; Shahabuddin, 2010; véase también el Estudio de caso 25.2). En la propia Periyar, un estudio independiente sugirió que los beneficios para las comunidades locales pueden ser menores a los que se afirman oficialmente (Gubbi et al., 2008).

Las principales debilidades comunes a muchas intervenciones de ICDP son: objetivos poco realistas y a menudo contradictorios; no identificación correcta de la fuente de amenazas y las intervenciones enfocadas consecuentes; un monitoreo deficiente que lleva a que sea difícil vincular de manera efectiva una mejor conservación con las actividades del proyecto, y la falta de apoyo a largo plazo para continuar con el desarrollo de capacidades y mantener las ganancias más allá de su duración (Alers et al., 2007). Otros incluyen la falta de capacidad para identificar y promover tradiciones, conocimientos, prácticas y cosmovisiones indígenas o locales que ayuden a la conservación, ya que gran parte del tiempo se ve a la gente local como "presiones" sobre el ecosistema y la vida silvestre, y no se comparte de manera significativa el poder sobre la toma de decisiones. 
Promover nuevas oportunidades de medios de subsistencia es solo una forma de beneficiar a las comunidades locales; es posible que otras estrategias sean más efectivas para alentar el apoyo a largo plazo respecto al cambio de comportamientos, como las oportunidades de empleo a través de emprendimientos turísticos (véase el Capítulo 23) o en el área protegida al ofrecer mano de obra o trabajo en la eliminación de especies exóticas invasoras. En otras partes, las áreas protegidas han tratado de abordar los problemas de equidad y sostenibilidad a través de microfinanzas o mecanismos de financiamiento a largo plazo con el fin de brindar recursos para actividades de desarrollo - por ejemplo, en varias áreas protegidas de Perú (PROFONANPE, 2012)-.

El monitoreo de todas las actividades del ICDP frente a los objetivos de reducción de amenazas y conservación de la biodiversidad es elemental. En algunos lugares podrá observarse un vínculo claro entre una mejor protección y la conservación -por ejemplo, un aumento de las poblaciones de peces en las áreas protegidas marinas o actividades de desarrollo y protección del hábitat. En otros lugares, los vínculos pueden ser menos evidentes. Cuando el monitoreo se enfoca más en el número de beneficiarios que en los resultados de la biodiversidad y la reducción de amenazas, es cada vez más difícil entender cuándo y dónde las intervenciones son eficaces para la conservación. A menos que los vínculos entre las actividades del proyecto y las metas de conservación sean claros y estén respaldados por las partes interesadas locales, es poco probable que el ofrecimiento de nuevas oportunidades de medios de subsistencia conduzca a beneficios en la conservación. El monitoreo participativo por parte de los miembros de la comunidad puede ser un complemento útil para el monitoreo realizado por el personal del área protegida gubernamental y los institutos de investigación (Margoulis y Salafsky, 2001; Danielsen et al., 2005).

El uso sostenible de los recursos suele ser un objetivo clave y un pilar de las áreas protegidas y otros sitios de conservación gobernados por actores no gubernamentales, incluidos los TICCA y las APP (véase el Capítulo 7). Por ejemplo, esto es la base de miles de bosques comunitarios en Asia del Sur, cientos de áreas marinas administradas localmente en el Pacífico Sur, el Sudeste Asiático y algunos países africanos, vastos territorios de pueblos nómadas en Asia Central y el Cuerno de África, y muchos otros TICCA (Borrini-Feyerabend et al., 2010; Bassi y Tache, 2011; Kothari et al., 2012; Naqizadeh et al., 2012; véanse también los Capítulos 7, 20 y 21). Esto también es una motivación clave para las APP, como aquellas que trabajan en la conservación de mamíferos grandes (y

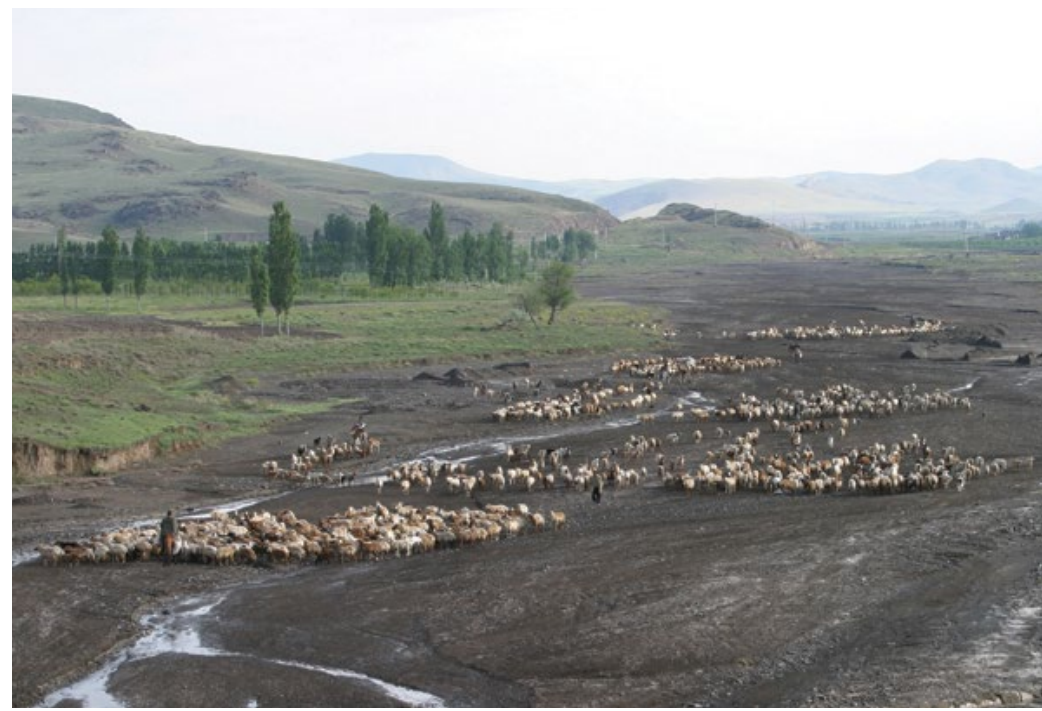

Pueblos móviles en migración a través de sus TICCA, Irán

Fuente: CENESTA

la vida silvestre asociada) en varios países africanos (véase en otros apartes de este capítulo).

\section{Reconocimiento del papel del uso sostenible en la conservación}

Cada vez más se reconoce que el uso sostenible de los recursos puede ser bastante compatible con los objetivos de conservación, así como contribuir con ellos. En algunos casos, los usos humanos tradicionales han hecho parte de la configuración del paisaje terrestre o marino en formas que los conservacionistas consideran importantes, o tales usos pueden proporcionar incentivos para la protección y los esfuerzos de conservación, o generar los ingresos necesarios para financiar las áreas protegidas. En algunos casos, la recolección puede aumentar la densidad del recurso - por ejemplo, en el desierto de Australia Occidental, los lagartos monitores de arena son más abundantes donde la caza es más intensa debido a las técnicas de quema por parches utilizadas por los cazadores aborígenes (Bird et al., 2013)-, aunque no está claro cuáles son los impactos generales sobre la biodiversidad.

En Guatemala, la cosecha y el comercio sostenibles de palmas pequeñas (para uso florístico en los países desarrollados) han permitido que las comunidades locales generen importantes ingresos, al tiempo que les brinda incentivos para mantener el recurso, lo cual conduce a la conservación del bosque. En la Reserva de la Biosfera Maya, el paisaje protegido más importante de Guatemala, las concesiones de uso sostenible respaldan una serie de prácticas de gestión privadas y comunitarias que llevan a una conservación más efectiva (Radachowsky et 
al., 2012). Todos los años, decenas de miles de tortugas laúd llegan casi simultáneamente a anidar en el Refugio Nacional de Vida Silvestre Ostional, Costa Rica. Las comunidades locales pueden recolectar un porcentaje de los huevos puestos "tempranamente", muchos de los cuales serían destruidos por los arribos posteriores. Este enfoque ha generado un enorme apoyo de la comunidad local para la conservación y prácticamente ha eliminado la recolección furtiva e ilegal de huevos a nivel local, mientras que la población de tortugas sigue aumentando (Campbell et al., 2007). En Brasil, la recolección tradicional de nueces de Brasil en los bosques amazónicos para obtener ingresos económicos ha resultado en una fuerte protección de estos bosques por parte de los recolectores contra los madereros y los ganaderos (Amazon Conservation Association, 2013).

En Europa Central, las llanuras de inundación del río Morava son ecosistemas seminaturales que ahora dependen por completo del manejo humano. En Eslovaquia, una gran área de las llanuras de inundación (casi cinco mil hectáreas) se incluyó en el Área de Paisaje Protegido de Záhorie. La forma más adecuada de gestión para mantener los valores de biodiversidad es la producción de heno. Esto evita que las praderas sean invadidas por la vegetación y que las especies invasoras se propaguen, y mantiene biotopos adecuados para la flora (por ejemplo, las orquídeas) y la fauna (por ejemplo, las mariposas) en peligro de extinción. El monitoreo ha confirmado que la biodiversidad es significativamente más alta en las praderas bajo un manejo regular que en las que no cuentan con dicho manejo (Rybanič et al., 1999). Por consiguiente, mantener este uso beneficia tanto a la conservación de la biodiversidad como al desarrollo socioeconómico local. Otro ejemplo que destaca la compatibilidad de la conservación y el uso de los recursos es el Parque Natural Lonjsko Polje, ubicado en las llanuras de inundación del río Sava en Croacia. Este parque es un ejemplo único de un paisaje evolucionado orgánicamente que mantiene usos tradicionales de la tierra, con la preservación de un sistema medieval de pastoreo en tierras comunes que fue típico de toda Europa Central hasta la segunda mitad del siglo XIX (Gugić, 2009). Este sistema tradicional de cría de animales se lleva a cabo con razas autóctonas de caballos, cerdos, reses y gansos.

En Irlanda, la geología local única y el clima del Burren (un paisaje cárstico en el noroeste del condado de Clare, gran parte del cual está designado como un área especial para la conservación) no solo han dado lugar a paisajes únicos, sino que también han contribuido al desarrollo de una forma distintiva de trashumancia conocida como "winterage" - una práctica tradicional de pastoreo que ha moldeado su patrimonio cultural y na- tural- (Parr et al., 2010). En los últimos cuarenta años, los factores socioeconómicos han contribuido a cambios significativos en la agricultura con impactos perjudiciales sobre la biodiversidad. Recientemente, esta tendencia se ha revertido a través del concepto de "agricultura para la conservación", que ha revitalizado el interés en la agricultura en winterages, lo que desempeña un papel fundamental en la restauración del paisaje y su biodiversidad. BurrenLIFE es el primer gran proyecto de "agricultura para la conservación" en Irlanda y marca la primera alianza de trabajo entre el Servicio Nacional de Parques y Vida Silvestre, la Autoridad de Desarrollo Agrícola y Alimentos y la sucursal de Burren de la Asociación Irlandesa de Agricultores (BurrenLIFE, 2014).

Las áreas protegidas en el este y el sur de África (con sus poblaciones de vida silvestre y condiciones de avistamiento excepcionales a nivel mundial) no solo tienen fines de conservación, sino que también generan ingresos y empleos a través del turismo. A su vez, estos ingresos financian los esfuerzos de conservación y crean incentivos a nivel local y nacional para las inversiones en la gestión de la vida silvestre (Spenceley, 2008; Child, 2004).

Los paisajes terrestres y marinos de satoyama y satoumi de Japón, conocidos por el uso altamente productivo de sus recursos, son cada vez más reconocidos como ejemplos de un uso sostenible que contribuye a la conservación (Bélair et al., 2010; UNU-IAS OUIK, 2011).

\section{Principios generales y enfoques para el uso de recursos en áreas protegidas}

\section{Derechos de uso y gobernanza}

Dos cuestiones importantes, y a veces controvertidas, son quién tiene los derechos de acceso y extracción de los recursos de un área protegida (terrestre o marina) y quién tiene el derecho a participar en la gestión (véase el Capítulo 7). Los derechos pueden surgir de la tenencia y prácticas indígenas, tradicionales o consuetudinarias, o pueden desarrollarse a través de políticas y legislación. Estos pueden mantenerse de manera comunitaria o individual, y pueden asignarse o transferirse permanentemente por compra. Los derechos de gestión especifican quién puede participar en la toma de decisiones para la gestión de áreas protegidas: tales derechos pueden ser ejercidos por gobiernos, pueblos indígenas y comunidades locales, o por alguna combinación de ambos (cogestión). Los derechos de uso especifican quién puede tener acceso a un área protegida o un recurso (derechos de acceso) y cuánta actividad (por ejemplo, el número de recolectores o días de pesca) o extracción (por ejemplo, 


\section{Estudio de caso 25.3 Protección de las zonas de pesca ancestrales de los Sangha-Sangha, República Centroafricana}

Los Sangha-Sangha son una comunidad pesquera en la zona de amortiguación del Parque Nacional Dzanga-Ndoki de la República Centroafricana. Debido a sus notables valores de biodiversidad, en 2012 el área fue inscrita en la Lista de Patrimonio Mundial como sitio trinacional de Sangha junto con los parques fronterizos de Camerún y Congo. Los cazadores-recolectores Baka y los Sangha-Sangha son los primeros habitantes de esta región. Con el tiempo, ellos desarrollaron una relación íntima y sinérgica con su territorio, la que ha definido sus valores, ha configurado su organización social y ha generado sofisticados sistemas de conocimiento y gestión ambiental. Un ejemplo de esto es un sistema interconectado de canales y zonas de inundación que los ancestros Sangha-Sangha crearon a lo largo del río Sangha, lo que brinda condiciones favorables de refugio y reproducción para los peces.

Desde la incursión de las compañías madereras en los años ochenta y noventa, los nuevos colonos han practicado técnicas de pesca insostenibles, incluido el uso de venenos. En respuesta, en 2008, los San-
gha-Sangha crearon la Asociación para el Desarrollo de los Sangha-Sangha (Association pour le Développement Sangha-Sangha, ADSS), con el objetivo de reinstituir la gobernanza local y las prácticas consuetudinarias. En 2012, la ADSS inició los diálogos con la administración del parque nacional y otras autoridades locales, y se concedió un decreto municipal que prohibía el uso de sustancias tóxicas de origen industrial y equipos no convencionales para la pesca, se asignaron derechos de pesca exclusivos a familias o clanes específicos reconocidos por las autoridades tradicionales, y se declaró que el incumplimiento de estas disposiciones podría dar lugar a un proceso penal. La entrada ilegal a los territorios ancestrales de los Sangha-Sangha y los métodos de pesca insostenibles se convirtieron en actos delictivos.

Desde entonces, la ADSS ha emprendido actividades para promover el uso sostenible de los recursos y fomentar la transmisión de conocimientos ecológicos y técnicas culturales, especialmente entre los jóvenes.

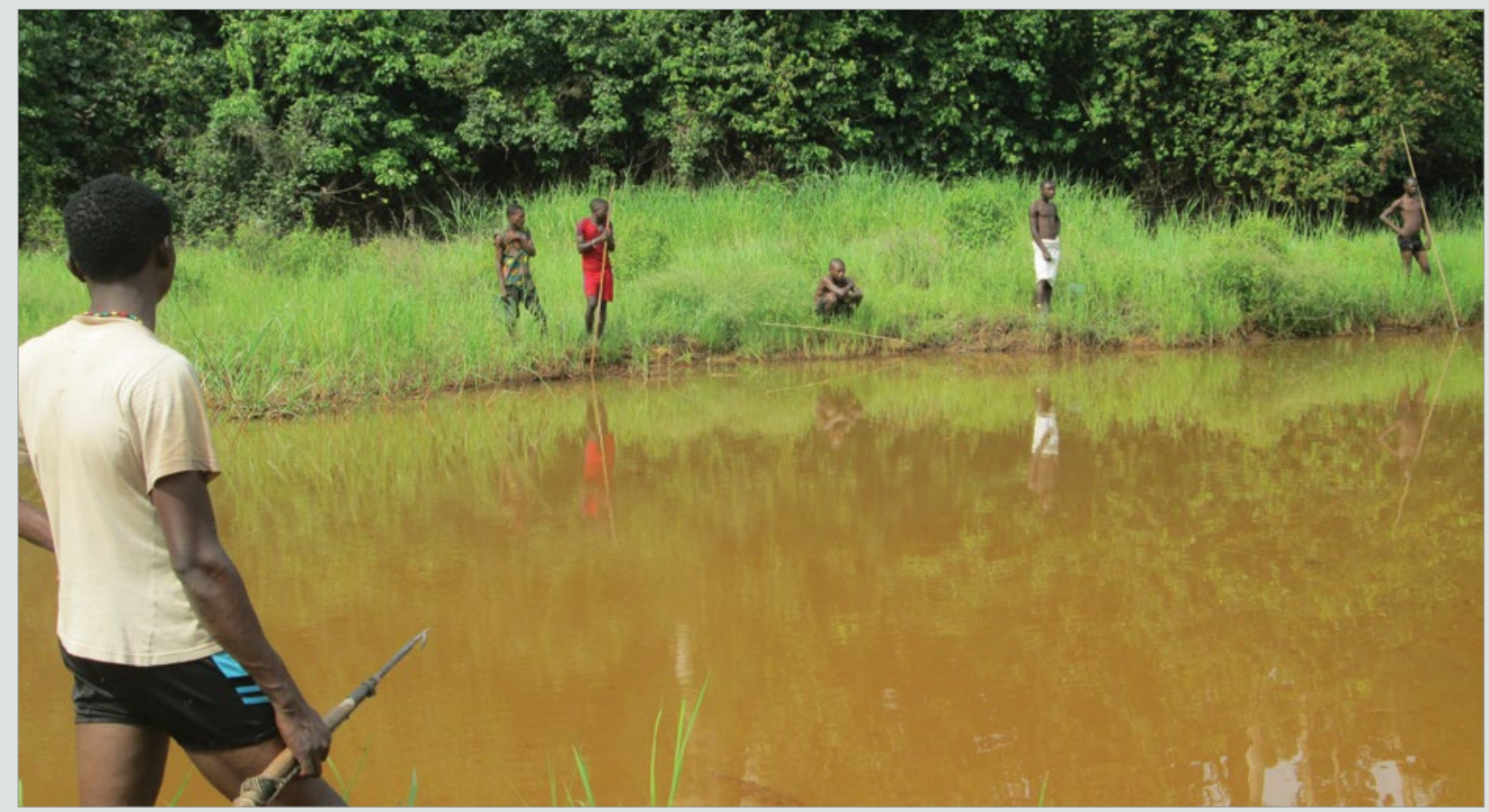

Miembros de la comunidad Sangha-Sangha en un humedal

Fuente: José Martial Betoulet

el volumen de leña o toneladas de captura) se permiten (derechos de extracción) (Charles y Wilson, 2009). Cada vez más se considera crítico el reconocimiento apropiado y equitativo de estos derechos de uso de los recursos para lograr una gestión eficaz del uso sostenible de los recursos (Charles y Wilson, 2009; Charles, 2011).

Un proceso constante de restitución o reconocimiento de derechos es el de la Ley sobre las Tribus y Otros Grupos Tradicionales que Habitan en los Bosques de India (Reconocimiento de los Derechos Forestales), acta 2006.
Bajo esta ley, pueden reconocerse y registrarse los derechos individuales y comunitarios a las tierras y recursos forestales que tradicionalmente existían pero que no se reconocían desde tiempos coloniales. Incluidos en esta ley están el derecho y los poderes para gobernar los bosques. Desde 2008, cuando entró en vigencia la ley, se han reconocido más de seis mil kilómetros cuadrados de tierras forestales (incluidas un par de áreas protegidas del Gobierno) y en algunos casos las comunidades hacen planes no solo con respecto a la mejor manera de 
conservarlas y utilizarlas de manera sostenible, sino también sobre cómo excluir lo que consideran actividades destructoras del "desarrollo" y la explotación maderera (Vasundhara y Kalpavriksh, 2012; Desor, 2013).

\section{Conocimiento tradicional e indígena}

La gestión eficaz de los recursos debe basarse en una buena información, la cual puede estar integrada en los sistemas de ciencia o conocimiento tanto indígenas como tradicionales y en las prácticas culturales prevalentes, o puede derivarse de métodos científicos occidentales, e idealmente de una combinación de estos (Posey, 1999; Failing et al., 2007; Tebtebba Foundation, 2008; Parrotta y Trosper, 2012). Por ejemplo, el conocimiento indígena/tradicional y local puede tener una importancia central en el mapeo de hábitats y áreas de uso de recursos, en el establecimiento de zonas de uso de recursos laboral y socialmente aceptables, en las estrategias centradas en la restauración del paisaje, en el aumento de la resiliencia de los ecosistemas y en una mejor adaptación al cambio climático (véase el Estudio de caso 25.3). Esto es particularmente importante en áreas protegidas marinas, verbigracia, donde los usuarios de los recursos locales tienden a tener un conocimiento profundo de las condiciones ambientales, la distribución y la abundancia de los recursos, y en contextos en los que los recursos son móviles y el monitoreo es difícil (Drew, 2005). En Eastport, en la isla de Terranova en Canadá, el conocimiento de los pescadores de la comunidad local sobre los posibles hábitats de cría de los juveniles de langosta sirvió como base para tomar decisiones respecto a las áreas vedadas para la pesca de langosta con el fin de mejorar la producción de huevos y aumentar el reclutamiento (Charles y Wilson, 2009). Este enfoque es típico de muchos TICCA y brinda lecciones para las áreas protegidas privadas o formales y administradas por el Gobierno (véase el Capítulo 7).

\section{Uso sostenible y equitativo}

La gestión del uso con el fin de lograr la sostenibilidad y la equidad es una prioridad fundamental para mantener los valores de biodiversidad. La Declaración de política de la UICN acerca del uso sostenible de los recursos vivos silvestres (IUCN, 2000) reconoce que el uso sostenible es una herramienta de conservación importante porque ofrece incentivos a las personas para la conservación en forma de beneficios sociales, culturales y económicos. Esto es más relevante en el caso de las áreas protegidas y también destaca la importancia de la gestión adaptativa, las limitaciones biológicas de las especies y los ecosistemas, las estructuras de gobernanza, si los usuarios tienen intereses formales o informales en los recursos que utilizan y la eliminación de incentivos perjudiciales. Por medio de un proceso de análisis regionales y estudios de casos globales liderado por la UICN, también se ha demostrado la importancia de una tenencia clara y segura de la tierra y los recursos como base para motivar a los usuarios locales a lograr un uso sostenible (Oglethorpe, 1999).

Bajo el Convenio sobre la Diversidad Biológica (CDB), en los Principios y Directrices de Addis Abeba, se elaboraron los principios para lograr el uso sostenible (uno de los tres objetivos principales del convenio) (CBD, 2004). Estos principios y documentos asociados proporcionan un marco importante para gestionar el uso de los recursos en áreas protegidas.

Al igual que con la sostenibilidad, la equidad socioeconómica es un componente crucial del uso de los recursos. Por ejemplo, incorporar aspectos de género en el pensamiento, la estrategia y la gestión de todas las formas de áreas protegidas es fundamental, de lo contrario el acceso y uso de los recursos por parte de las mujeres podría verse marginado (FAO, 2012; Harper et al., 2013). Debe reconocerse la importancia de las mujeres dentro de la pesca, en particular en los sectores anteriores y posteriores a la recolección. A menudo, las mujeres en las comunidades pesqueras carecen de acceso a la pesca y se les puede negar un papel en la toma de decisiones debido a las normas culturales existentes; pueden además enfrentar problemas más grandes como la falta de crédito y servicios de transporte, y la subestimación de su trabajo. Del mismo modo, las desigualdades en el acceso a los recursos, como las que existen entre diferentes grupos étnicos, clases, castas y otras divisiones sociales, podrían obstaculizar seriamente el uso sostenible de los recursos y deben abordarse con sensibilidad.

\section{Gestión del uso de los recursos en áreas protegidas: enfoques y ejemplos}

La gestión del uso de los recursos en las áreas protegidas debe ser no solo altamente sensible al contexto, sino también receptiva a la forma de uso involucrado, a las características del recurso y al contexto socioeconómico. En esta sección se discuten algunos de los principales tipos de uso basados en ejemplos provenientes de una amplia variedad de regiones. 


\section{Recolección de productos vegetales silvestres (uso y comercio local)}

Los bosques, humedales, pastizales y ambientes marinos protegidos son la fuente de una amplia gama de productos forestales no maderables (PFNM), definidos como todos los materiales biológicos diferentes a la madera en rollo industrial y los productos resultantes que se recolecten al interior y en los bordes de bosques manipulados o perturbados (Chamberlain et al., 2004). Si bien el término puede incluir tanto productos vegetales como animales, esta sección se enfoca principalmente en productos vegetales, con una discusión de los productos de origen animal en la siguiente sección. Los PFNM son de gran valor económico y de subsistencia. Por ejemplo, Schippmann et al. (2006) estiman que hasta setenta mil especies de plantas superiores (alrededor del 20\% de la flora mundial estimada) se utilizan como medicina en todo el mundo, de las cuales alrededor de tres mil se comercializan internacionalmente. Además, se ha estimado que las plantas son la principal forma de medicina disponible para el $80 \%$ de la población mundial (Kamboj, 2000, Parrotta y Trosper, 2012). Solo en India, cerca de 275 millones de personas dependen de los PFNM, con el uso de más de diez mil especies de plantas y animales para alimento, combustible, forraje, medicinas, vivienda, implementos y usos culturales (TPCG y Kalpavriksh, 2005). El valor global de los PFNM en 2005 alcanzó \$16.839 millones de dólares (FAO, 2010). Esto incluye el uso extenso y generalizado al interior y alrededor de las áreas protegidas.

Los recolectores de PFNM participan cada vez más en emprendimientos comerciales impulsados por la demanda del mercado nacional y mundial, con la ruptura de estructuras de administración tradicionales, lo cual amenaza la sostenibilidad de la base de recursos. Por ejemplo, la industria de la medicina alternativa en Europa, Norteamérica, Australia y Nueva Zelanda utiliza una amplia variedad de hierbas medicinales, y ha adoptado muchas de las prácticas de las medicinas tradicionales ayurvédicas, budistas y chinas, por lo que se ha convertido en una industria multimillonaria de rápido crecimiento. La recolección de plantas medicinales silvestres se ha convertido en un emprendimiento comercial organizado en muchos lugares, donde los agentes emplean a personas locales para la recolección (Battharai et al., 2003). Esto también es una preocupación con otros productos de la vida silvestre, como el marfil, con un importante aumento reciente en la caza furtiva para satisfacer la demanda de los nuevos ricos en Asia (CITES, 2013).

Por lo general, los hotspots de biodiversidad vegetal se encuentran en países tropicales con un Índice de Desa- rrollo Humano (IDH) bajo, donde puede ser alta la presión para aumentar el desarrollo económico y humano. En muchas áreas protegidas, los administradores tienen la responsabilidad de determinar si la cosecha de plantas, el pastoreo u otros usos a largo plazo tienen implicaciones benéficas, perjudiciales o neutrales para lograr los objetivos de gestión; en otras, esta es una responsabilidad de las comunidades de usuarios $\mathrm{u}$ organizaciones de la sociedad civil. En algunas, existen sistemas bien establecidos y científicamente rigurosos para medir, controlar, evaluar e informar sobre las actividades (véase el Capítulo 28). También es necesario determinar a qué nivel es sostenible la actividad y establecer límites, lo cual se hace mejor con la participación de las comunidades de usuarios locales. Por ejemplo, la cosecha de pastos en un área de humedal puede ser benéfica para el hábitat de las aves, pero el aumento o la disminución de la recolección o los cambios en la forma en que se lleve a cabo puede hacer que la actividad sea perjudicial. Siempre que sea posible, es deseable un monitoreo constante de las condiciones ambientales y sociales para evaluar el impacto de tales actividades. En todo el mundo, muchos TICCA y áreas protegidas comanejadas emplean métodos de monitoreo, que van desde indicadores tradicionales y puntos de referencia que suelen basarse en siglos de observación, hasta los más modernos, que suelen ser más cuantificados (Estudio de caso 25.4).

En las nuevas herramientas para evaluar la sostenibilidad de la recolección de plantas medicinales y otras plantas silvestres, como el Estándar FairWild, se están incorporando medidas para evitar la sobreexplotación y otras para evaluar los aspectos ecológicos y sociales (FairWild, 2009; Kathe et al., 2010; Kathe, 2011; Unnikrishnan y Suneetha, 2012). Los planes de manejo de especies también son un mecanismo para monitorear y prevenir la sobreexplotación (Estudios de caso 25.4 y 25.5). Los esfuerzos de la política internacional en torno al uso sostenible de los recursos vegetales incluyen, entre otras, las Directrices Sobre la Conservación de las Plantas Medicinales (actualmente en revisión) de la Organización Mundial de la Salud (OMS), y la Estrategia Mundial para la Conservación de las Especies Vegetales bajo el CDB (Unnikrishnan y Suneetha, 2012). En el caso de las áreas protegidas administradas por el Gobierno, quizás sea necesario negociar con las comunidades para detener las prácticas que dañen el área protegida. En el caso de los TICCA, es frecuente que los miembros de la comunidad lleven a cabo estas negociaciones internamente, y quizás tengan que lidiar con presiones tanto internas como externas (Estudio de caso 25.3). En India, los nuevos enfoques para salvaguardar y conservar las plantas medicinales incluyen el establecimiento de áreas 


\section{Estudio de caso 25.4 Cómo se enfrenta la sobreexplotación a través de la negociación y la acción comunitaria en Uganda e India}

El Parque Nacional Kibale en Uganda (categoría de la UICN no definida) ilustra el éxito de un enfoque de negociación. El parque está rodeado por veintisiete parroquias en las que viven aproximadamente ciento veinte mil personas. Las comunidades en los límites extraen más de veinte productos del parque para satisfacer algunas de sus necesidades comerciales, culturales, medicinales y de subsistencia. Si bien la prohibición fue la primera estrategia de manejo que se intentó, se descubrió que la aplicación de la ley requería mucho tiempo y era costosa para los administradores de los parques. Se descubrió que la mayoría de las actividades ilegales procedían de las comunidades fronterizas. Con la ayuda del Proyecto de Conservación y Desarrollo Kibale Semuliki se negociaron acuerdos colaborativos de gestión de recursos con las comunidades fronterizas locales, en los que se establecieron límites acordados sobre quién podía recolectar en el parque y qué productos podían extraerse. Tomó dos años identificar, negociar y firmar los primeros acuerdos y un promedio de seis meses para los siguientes acuerdos. El éxito de los acuerdos colaborativos aumentó cuando se brindaron apoyos para desarrollar alternativas a la recolección de recursos en el parque. Las relaciones entre la comunidad y el parque mejoraron, se notó un declive significativo en las actividades ilegales y los miembros de la comunidad se involucraron en la denuncia de actividades ilegales (Chhetri et al., 2003).

La aldea de Mendha-Lekha en India, con un bosque conservado por la comunidad de casi dos mil hectáreas, ha liderado una serie de movimientos asertivos para recuperar los derechos sobre los bosques comunitarios y evitar que una planta papelera reduzca drásticamente el hábitat local de bambú. Después de obtener el título legal en virtud de la Ley de Derechos Forestales de 2006, esta aldea ha reforzado sus normas y regulaciones consuetudinarias, y las ha actualizado para incluir la recolección sostenible de bambú (que anteriormente estaba bajo el control del Departamento Forestal del Estado). Ahora la aldea obtiene ingresos sustanciales de esto, y el dinero depositado en la cuenta de la aldea se utiliza en la generación de medios de subsistencia para los aldeanos a través de actividades relacionadas con el desarrollo forestal, designación de hábitats de vida silvestre y otras actividades. La aldea ahora puede ofrecer salarios justos y préstamos oportunos, no solo a los residentes sino también a otros aldeanos que deseen trabajar en la aldea (siempre que cumplan las normas locales) (Pathak Broome y Dash, 2012).

\section{Estudio de caso 25.5 Plan de manejo de especies para el árbol de canela (Cinnamomum capparu-coronde)}

El árbol de canela (Cinnamomum capparu-coronde) es una especie medicinal endémica altamente amenazada en Sri Lanka. La Reserva de la Biosfera de Kanneliya-Dediyagala-Nakiyadeniya (KDN) en el sur de Sri Lanka alberga poblaciones sustanciales, conocidas localmente como "Kapuru Kurundu". Existen 78 aldeas alrededor de la reserva; el $50 \%$ de los hogares viven por debajo del umbral de la pobreza y dependen del bosque para la madera y los PFNM. El árbol de canela se usa localmente para curar bronquitis, reumatismo, mordeduras de serpientes, fracturas y dolor de dientes, entre muchas otras dolencias. El eugenol es un importante ingrediente químico que se extrae de la planta.

En un intento por evitar la sobreexplotación de esta importante especie endémica, la reserva forestal KDN fue seleccionada para desarrollar e implementar un plan de manejo de especies. El objetivo es mantener la población de Kapuru Kurundu por medio del monitoreo de los cambios en la densidad entre 2009 y 2019 en dos macroparcelas dentro de la reserva KDN. La implementación del plan la realiza el Departamento Forestal con el apoyo de comunidades locales e investigadores de la Universidad de Ruhuna y otras agencias. En el plan de manejo de la reserva, al cual está vinculado el plan de manejo de especies, el Departamento Forestal también tuvo en cuenta las necesidades económicas y culturales más amplias de las comunidades que viven en la periferia de la reserva.

Fuentes: Sathurusinghe et al., 2010; Hunter y Heywood, 2011 para la conservación de plantas medicinales (Medicinal Plant Conservation Areas, MPCA) y los parques para la conservación de plantas medicinales (Medicinal Plant Conservation Parks, MPCP) (Unnikrishnan y Suneetha, 2012). Hasta 2012, se habían establecido 112 MPCA en trece estados de India. Otras estrategias incluyen limitar la extracción de recursos a ciertas áreas, permitir que solo personas específicas recolecten el recurso, establecer cuotas basadas en un rendimiento sostenible y plantar las especies codiciadas fuera del área protegida.

\section{Caza y pesca}

En algunas áreas protegidas se llevan a cabo diferentes formas de caza y pesca, de manera legal e ilegal, para fines comerciales y de subsistencia. Durante mucho tiempo, la caza de animales silvestres ha sido importante para las 


\section{Estudio de caso 25.6 Manejo de la caza en áreas protegidas estatales, norte de Finlandia}

En el norte de Finlandia, incluidas las regiones de Laponia, Kainuu y partes de Ostrobotnia del Norte, los residentes locales tienen permitida la caza en la mayoría de los parques nacionales y otras reservas naturales protegidas, si esto no amenaza los objetivos recreativos o de conservación. En el norte de Finlandia, cerca de cincuenta mil personas tienen tales derechos. En la mayoría de las otras reservas naturales protegidas, los no residentes también tienen permitida la caza con licencia. La caza está prohibida en las reservas naturales estrictas.

Las regulaciones para la caza se describen en el decreto o ley de cada reserva natural. Las restricciones pueden ser temporales o territoriales, y específicas por especie. Los planes de gestión se preparan con la participación de las partes interesadas locales. Todas las especies de caza tienen temporadas de caza nacionales o regionales fuera de los períodos vulnerables o de reproducción. Si una población se ve amenazada, la temporada de caza se restringe con un decreto del Ministerio de Agricultura y Silvicultura.

Las principales partes interesadas con derechos de uso tradicional incluyen pastores de renos representados por asociaciones de pastores y su federación nacional (su área en el extremo norte de Finlandia cubre una tercera parte del país), y los lapones que tienen aquí sus tierras natales tradicionales. Más del $90 \%$ de esta área pertenece al Estado y es administrada por el Metsähallitus, la agencia nacional de áreas protegidas de Finlandia. El pueblo lapón tiene una larga tradición en el pastoreo de renos y la captura del lagópodo común (Lagopos lagopus). Las asociaciones para el manejo de la caza representan los intereses de los cazadores residentes.

Los resultados de los censos de vida silvestre demuestran las fluctuaciones naturales y la estabilidad a largo plazo en las poblaciones de caza en el norte de Finlandia. Con base en esto, puede considerarse que el sistema de manejo de la caza es ecológicamente sostenible. Los mayores desafíos se relacionan con la sostenibilidad social, lo cual afecta el trabajo voluntario del cual dependen los censos triangulares de vida silvestre y las medidas de control de depredadores invasores, como el perro mapache (Nyctereutes procyonoides) y el visón americano (Neovison vison).

Mikko Rautiainen comunidades rurales y muchas áreas protegidas permiten una caza y pesca de subsistencia limitada. La carne de monte es un término que suele utilizarse para describir la carne obtenida de la caza de animales silvestres, principalmente en ambientes forestales de países donde el ganado doméstico no es común. Esta es ahora una importante actividad comercial y de subsistencia en África y, en menor medida, en Suramérica y Asia. En algunas áreas, como la cuenca del Congo, esta actividad satisface la mayoría de las necesidades humanas de proteínas y grasas. Con una pequeña inversión de capital necesaria para involucrarse en esto, los hombres jóvenes en las comunidades pobres pueden participar fácilmente, y el comercio descentralizado significa que una gran parte del valor de los bienes va al productor primario (el cazador) (Nasi et al., 2008, 2011; van Vliet et al., 2012; Schulte-Herbrüggen et al., 2013).

En África, 42 especies de mamíferos de interés para la conservación global se ven afectadas por el comercio de carne de monte, incluidos chimpancés, elefantes y gorilas (CITES, 2000; Redmond et al., 2006). Las estructuras de gobernanza débiles a nivel local y las malas prácticas industriales dificultan la regulación y la gestión del comercio.

Las fuerzas del mercado pueden crear un valor para la vida silvestre y ofrecer incentivos para la conservación privada o comunitaria, y también pueden impulsar la sobreexplotación de las poblaciones. En el Parque Nacional Cuc Phuong, Vietnam, la caza ilegal ha reducido las poblaciones de grandes mamíferos y los conflictos con las poblaciones humanas locales obstaculizan el manejo efectivo (Compton y Le, 1998; McNeely, 1998). Muchas áreas acuáticas protegidas enfrentan problemas de sobrepesca por la incursión de las comunidades vecinas o por la presencia ilegal de operaciones a gran escala. En la Gran Barrera de Coral de Australia, la pesca de arrastre de langostinos a gran escala, tanto con licencia como ilegal, ha reducido a la mitad las poblaciones de algunas especies; por cada tonelada de langostinos capturados, se sacrifican entre seis y diez toneladas de otras especies marinas. El organismo de investigación del gobierno australiano, la Organización de Investigación Científica e Industrial de la Commonwealth (CSIRO), identificó cincuenta operadores ilegales en el área de 362.400 kilómetros cuadrados (Australian Committee for IUCN, 1999; Zinn y Vidal, 1999).

En los casos en que tales actividades se restringen o prohíben, a veces se ofrece una compensación por la pérdida de ingresos (particularmente si el uso era legal). Este es el caso de la recolección de plantas medicinales en el Himalaya de India (véase el Estudio de caso 25.2). A menudo, esto también se hace en los TICCA, donde la decisión colectiva de detener alguna actividad de uso de recursos o cambiar el uso de la tierra se compensa por medio de nuevas oportunidades de medios de subsistencia, como el turismo comunitario o la entrega de tierras en otros lugares. En India, en el humedal de Mangalajodi protegido por la comunidad, una decisión de la comunidad inspirada por una organización de la sociedad civil para detener la caza de aves acuáticas fue seguida por un emprendimiento de ecoturismo que empleó a algunos de 
los antiguos cazadores (Kothari, 2010). No obstante, es posible que en tales casos las medidas compensatorias no coincidan con la escala de la pérdida.

En los sitios con una gestión adecuada, la caza puede ser sostenible y contribuir al manejo y la conservación del área protegida (Estudio de caso 25.6), y cada vez más se reconoce que enfrentar el problema de la carne de monte, como en África, requiere que se establezca un uso sostenible legalmente regulado de los recursos de carne a partir de animales silvestres (Nasi et al., 2008). En algunos casos, esto se ha logrado a través de acuerdos con las comunidades locales o al hacer que el manejo de la vida silvestre sea responsabilidad de las comunidades locales. En muchos de los TICCA relativamente nuevos, puede adoptarse una combinación de restricciones tradicionales y nuevas (véase el Capítulo 7). Por ejemplo, en el estado de Nagaland en India, varias docenas de aldeas declararon prohibiciones estacionales sobre la caza o designaron áreas forestales donde está totalmente prohibida (Kothari y Pathak, 2005). Las áreas protegidas privadas pueden incluir la caza sostenible para aumentar los ingresos - por ejemplo, la Reserva de Caza Privada Campbell en Sudáfrica, la cual se administra con fines comerciales, ofrece experiencias de caza que se asemejan a las de los bosquimanos del Kalahari, dentro de límites sostenibles (Campbell Private Game Reserve, 2004, citado por Lockwood et al., 2006)-.

En particular, la caza turística o de "trofeos" con tarifas altas se lleva a cabo en muchas formas de áreas protegidas a lo largo del África subsahariana, África meridional y Tanzania. La mayor parte de estas actividades de caza de trofeos tiene lugar en tierras privadas y algunas tierras comunales. Algunas se llevan a cabo en áreas protegidas administradas por el Estado. En Tanzania, aproximadamente la mitad de todas las concesiones de caza se ubican en áreas protegidas estatales llamadas "reservas de caza", donde no residen personas, así como en áreas de caza controlada (Game Controlled Areas, GCA), en las que la Ley de Conservación de la Vida Silvestre de 2009 prohibió recientemente la residencia y el uso humano. Esta disposición de la Ley de 2009 es extremadamente problemática, ya que antes de 2009 las GCA no eran áreas protegidas excluyentes, $y$ en todo el país albergaban entre quinientos mil y un millón de personas. En 2013, después de que el gobierno propusiera que mil quinientos kilómetros cuadrados de antiguas tierras comunitarias se convirtieran en un GCA excluyente o "corredor de vida silvestre", se presentó un conflicto de grandes proporciones sobre el GCA de Loliondo (Ngoitiko y Nelson, 2013). En Tanzania, por cincuenta años se han disputado tales contiendas entre la conservación de la vida silvestre, los usos comerciales como la caza y los dere-

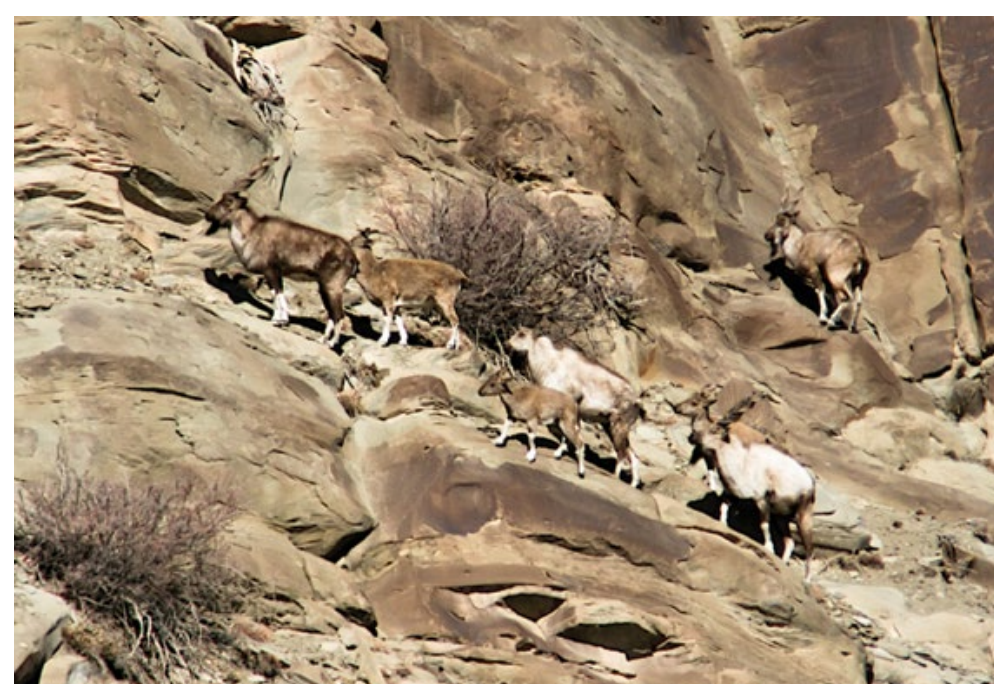

Marjor (Capra falconeri) en la zona conservada de la comunidad de Torgarh, Beluchistán, Pakistán

Fuente: Tahir Rasheed

chos sobre las tierras y los recursos locales. La cacería en las reservas de caza se basa en la división de estas áreas protegidas en "bloques" o áreas de concesión, y el Ministerio de Recursos Naturales y Turismo concede una cuota anual para cada bloque. La caza brinda una importante justificación económica para conservar esta tierra como hábitat de vida silvestre, aunque es evidente que existen debilidades considerables con respecto a la gobernanza y regulación de la caza, incluida la corrupción (Leader-Williams et al., 2009; Nelson et al., 2013).

En Namibia, bajo el modelo de conservación comunitaria, las comunidades generan ingresos a través del turismo fotográfico y de caza, la venta de animales de caza vivos y la "cosecha de animales de caza" para carne y pieles. Este enfoque aumentó drásticamente el valor social y económico de la vida silvestre para las personas, transformó las actitudes y condujo a cambios a gran escala en el uso de la tierra, desde tierras pastoriles degradadas hasta la conservación de la vida silvestre, con una recuperación de las poblaciones de especies como elefantes y rinocerontes blancos y negros (Naidoo et al., 2011; Nelson et al., 2013).

La caza de trofeos de grandes animales en Pakistán ha emergido como una aproximación a la conservación que ayuda a mejorar los medios de subsistencia locales (Frisina, 2000; Frisina y Tareen, 2009). El marjor, el urial y el íbice son algunas de las principales especies de vida silvestre que se encuentran en diferentes partes de Pakistán y que tienen un mercado internacional para la caza de trofeos. No obstante, debido a la caza a gran escala y la pérdida de hábitat, las poblaciones de estas y otras especies han disminuido progresivamente desde la época colonial. La idea de la caza de trofeos organizada 


\section{Estudio de caso 25.7 Pastoreo sostenible en el Parque Nacional Retezat, Rumania}

El Parque Nacional Retezat es el parque nacional más antiguo de Rumania. Este protege un rincón único de las montañas de los Cárpatos y contiene un rico ensamblaje de plantas y poblaciones viables de varios mamíferos grandes. El parque fue designado como reserva de la biosfera en 1979.

El pastoreo tradicional todavía se practica; más del $20 \%$ de las áreas alpinas son pasturas de propiedad y uso de los aldeanos locales. Los derechos de los aldeanos a estas pasturas se remontan a un acuerdo gubernamental de 1922; sin embargo, con los años ha disminuido el control local sobre el pastoreo en esta área y ahora presenta un sobrepastoreo, lo que ha alterado la diversidad natural y la riqueza de los pastizales alpinos. El desafío para la autoridad de administración del parque ha sido alentar a las personas locales a volver a niveles sostenibles de pastoreo.

El Proyecto Rumano de Gestión para la Conservación de la Biodiversidad ha financiado proyectos que promueven el pastoreo sostenible en las pasturas alpinas. Se ha establecido un comité de subvenciones, el cual incluye representantes de todas las comunidades con derechos de propiedad u otras participaciones en el parque. La población local recibe capacitación para mejorar sus capacidades de redacción de proyectos y actividades de recaudación de fondos.

Desde 2001, las autoridades locales han ayudado en el desarrollo de protocolos y programas conjuntos que no solo establecen normas para las actividades de pastoreo, incluso dentro de la zona central del parque, sino también protegen los derechos de pastoreo de los propietarios locales de animales. Como resultado, desde 2002 se ha observado una disminución en el nivel de actividades de pastoreo en los prados alpinos. Una evaluación en 2013 reconoció estos esfuerzos de gestión y recomendó proseguir con el Diploma Europeo de Áreas Protegidas del parque.

Fuentes: adaptado de Wieting, 2004; Galland, 2013 cados (Brown y Kothari, 2011; van Oudenhoven et al., 2011). En Oaxaca, México, 126 sitios de conservación comunitaria repartidos en 375.500 hectáreas incorporan sistemas agroforestales y agroecológicos, como milpas y plantaciones de café con sombrío, lo que convierte a estas áreas en importantes reservorios de vida silvestre y agrobiodiversidad. En el Parque de la Papa cerca de Pisac, Perú, seis comunidades indígenas quechuas conservan su paisaje para que la agricultura y el pastoreo sean ecológicamente sostenibles y biológicamente diversos (Argumedo, 2008).

\section{Pastoreo de ganado}

Algunos estudios han encontrado que ciertos niveles de pastoreo, además de ser sostenibles, también pueden ser esenciales para mantener ciertos pastizales altamente diversos, y la eliminación de la gente y el ganado conduce a una disminución de la biodiversidad en el área protegida (Infield, 2003; Parr et al., 2010; Nelson, 2012). En África y Asia Occidental, pastores nómadas condujeron sus ganados en algunas áreas de forma sostenible durante siglos. Es frecuente que, cuando las culturas tradicionales se basan en el cuidado de rebaños, los sistemas establecidos por ellas durante largos períodos no solo moldeen el paisaje, sino también que su uso se vuelva esencial para mantener los procesos ecológicos y la biodiversidad (Farvar, 2003; Borrini Feyerabend et al., 2004; véanse también las referencias en la sección "Agricultura" de la información anterior). En Europa, gran parte de la biodiversidad en las áreas protegidas se desarrolló conjuntamente con las prácticas pastoriles tradicionales (Estudio de caso 25.7).

Incluso cuando el pastoreo de ganado no es parte de un paisaje biocultural establecido desde hace mucho tiempo, a veces puede ser útil para cumplir con los objetivos de gestión de las áreas protegidas. Por ejemplo, en Costa Rica, el pastoreo se ha utilizado en la restauración del ecosistema del bosque tropical seco del Parque Nacional Guanacaste para la dispersión de semillas, el control de pastos exóticos y la generación de apoyo local (Evans, 1999). En el Parque Nacional Palo Verde, también en Costa Rica, el pastoreo de ganado ha ayudado con la conservación de un humedal en particular (Vaughan et al., 1996).

No obstante, las decisiones sobre el pastoreo de ganado en áreas protegidas deben tomarse caso por caso. En Australia, una extensa investigación demostró que el pastoreo de ganado causa daños considerables a la vegetación nativa alpina y subalpina, a los suelos y a las vías fluviales en el Parque Nacional Kosciuszko y en el Parque Nacional Alpino (Williams, 1990; Wahren et al., 1994). En algunas áreas protegidas, las presiones para aumentar la producción agrícola han llevado al sobrepastoreo, pero en lugar de una prohibición, se han desarrollado medidas participativas para minimizar el daño (Estudio de caso 25.7). En muchos TICCA (véase el Capítulo 7) -por ejemplo, los bosques comunitarios en Asia del Sur- las comunidades regulan voluntariamente el pastoreo mediante un cese temporal o estacional de toda la actividad de pastoreo, lo que permite la regeneración de los paisajes degradados.

\section{Uso de recursos marinos y costeros}

Con frecuencia, los ecosistemas costeros en áreas marinas protegidas (AMP) tienen un uso importante de recursos con fines comerciales y de subsistencia (Spalding et al., 2013). La recolección incluye recursos comestibles como peces de aleta, mariscos, mamíferos marinos y algas ma- 


\section{Estudio de caso 25.8 Área Marina de Manejo de Soufrière, Santa Lucía}

El área marina de manejo de Soufrière en Santa Lucía es un área de usos múltiples que incluye reservas marinas de no extracción, zonas prioritarias de pesca y zonas de otros usos. Antes de su establecimiento en 1994, eran constantes y numerosos los conflictos entre los pescadores tradicionales locales, los turistas, los visitantes de un día y los yatistas que navegaban por las Indias Occidentales. Los buzos visitantes hacían agujeros en las trampas para peces con el fin de liberar los peces de arrecife; los yatistas anclados en bahías arenosas interferían con la pesca local de peces pelágicos costeros, y las instalaciones turísticas tenían restringido el acceso a la playa y al mar.

Las poblaciones de peces de arrecife estaban bajo amenaza por la pesca submarina ilegal y la pesca con jaulas, y las anclas dañaban el arrecife (Salm et al., 2000).

En 1992, el Departamento de Pesca y el Instituto de Recursos Naturales del Caribe iniciaron la negociación, la resolución de conflictos y la planeación participativa. Se realizó un mapeo de todos los usos y se llegó a un acuerdo preliminar para zonificar once kilómetros de costa. La implementación de esto fue exitosa; sin embargo, solo por dos o tres años, luego de lo cual dejó de funcionar debido a violaciones por algunas de las partes, ya que el acuerdo no tenía un respaldo legal. Después de una completa revisión institucional, se desarrolló un nuevo régimen de administración basado en una misión claramente acordada, una estructura de gestión transparente y una sólida base legal (Salm et al., 2000; Geoghegan y Renard, 2002).

En 2005, el Área Marina de Manejo de Soufrière celebró su décimo aniversario. Un estudio anterior a esto mostró que la biomasa de peces comerciales en la reserva marina se multiplicó por cuatro y en la zona de pesca se triplicó. Gracias a las tarifas de buceo y de amarre para yates el área se volvió autosuficiente desde el punto de vista financiero. La capacidad institucional aumentó en todos los grupos de partes interesadas y el turismo trajo beneficios a la comunidad local (Gell y Roberts, 2002). Los desafíos siguen apareciendo, pero todas las partes interesadas están comprometidas cuando se trata de enfrentarlos. rinas; recursos para construcción tales como postes de manglar, bloques de coral, arena y cal; recursos para uso ornamental como conchas, perlas y coral; para uso científico, lo que incluye una amplia gama de especies; para uso industrial, como almejas gigantes y especies de las que se extraen productos farmacéuticos, y para la maricultura, como los mejillones y las ostras. Cada vez más, el ecoturismo y la educación son componentes importantes del uso del medioambiente marino.

En muchos casos, la protección de las pesquerías sostenibles es uno de los objetivos principales de la designación del AMP. En la isla de Terranova en Canadá, el AMP comunitaria de Eastport fue motivada por la dependencia histórica de la comunidad local en la pesca y uno de sus objetivos fue salvaguardar las poblaciones de langosta, en particular después del colapso de las poblaciones de peces del fondo marino y la disminución de capturas en la pesca de langosta (Charles y Wilson, 2009). Del mismo modo, parte de la motivación para que las comunidades establezcan y administren la ahora extensa red de áreas marinas manejadas localmente (Locally Managed Marine Areas, LMMA) en el Pacífico Sur es garantizar que estas áreas ofrezcan un flujo sostenible de beneficios pesqueros (Govan, 2009).

$\mathrm{Al}$ igual que con el uso de los recursos terrestres, las sociedades indígenas y tradicionales contaban con regulaciones en el derecho consuetudinario para brindar una protección contra el uso excesivo de los recursos marinos. Por ejemplo, en Corea, son las mujeres las que tradicionalmente bucean. Ellas se autorregulan al acordar el no uso de equipos de buceo, aunque estén disponibles, de modo que todo lo que tomen sea lo que puedan reco-

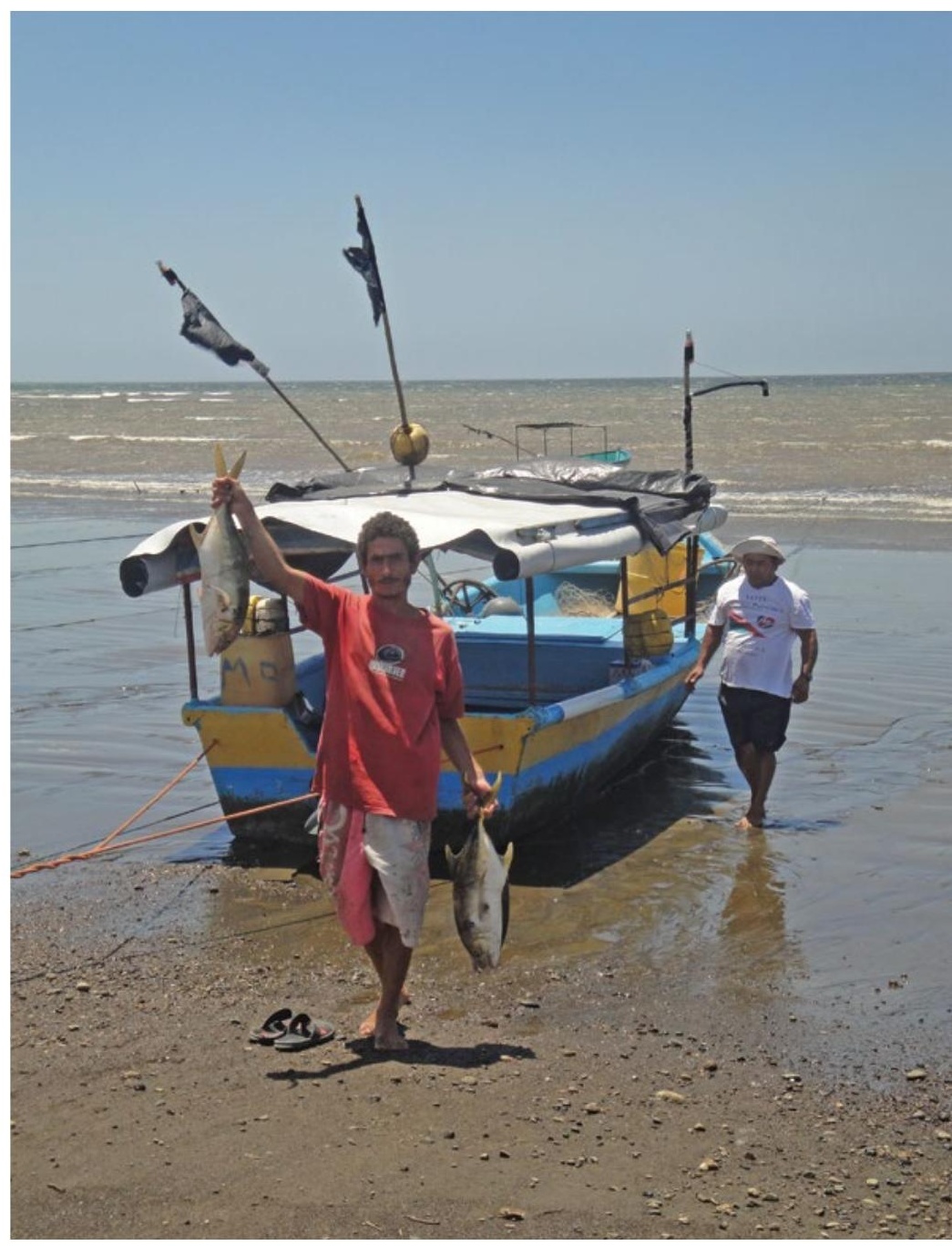

Área Marina de Pesca Responsable de Tárcoles, Costa Rica

Fuente: CoopeSolidar RL 
lectar aguantando la respiración y buceando de la manera tradicional. Ellas recolectan pulpos, abulones, erizos de mar, babosas de mar, pepinos de mar y algas marinas, y comercializan sus productos desde la década de 1970 (Onishi, 2005; Pfeiffer, 2009).

En Costa Rica, después de dos años del reconocimiento del Área Marina de Pesca Responsable de Tárcoles y la presentación de estudios por parte de los pescadores a las instituciones estatales, las comunidades pesqueras locales recibieron un permiso de uso sostenible por tres meses (Madrigal Cordero y Solís Rivera, 2012). En estos lugares los sistemas autorregulados aún funcionan de manera eficaz, aunque es frecuente que los cambios en la tenencia y el uso de la tierra interrumpan las prácticas en vigor durante milenios. Al noreste de Madagascar, en el Parque Marino Nosy Atafana, parte de la Reserva de la Biosfera de Mananara-Nord de la Organización de las Naciones Unidas para la Educación, la Ciencia y la Cultura (UNESCO), un acuerdo entre las autoridades de la reserva y las comunidades locales especifica las actividades permitidas y prohibidas relacionadas con el pulpo, el pepino de mar y otras especies de la fauna (IUCN, 2004).

No obstante, las AMP siguen manejándose de manera excluyente en muchas partes del mundo, lo que lleva a la suspensión o restricción incluso de los usos tradicionales que no van en detrimento de la biodiversidad, o a otros modos de despojo de las comunidades locales -uno de sus resultados es el empeoramiento de hostilidades hacia las AMP-. Cuando un proceso consultivo y negociado está en capacidad de demostrar que las zonas de no extracción pueden ayudar a aumentar las poblaciones de peces fuera de ellas, hay más posibilidades de que las personas acepten una variedad de estrategias, incluida la exclusión estricta de algunas áreas o durante un período determinado, por ejemplo, en la Reserva de la Biosfera Seaflower en Colombia (Friedlander et al., 2003). En algunos casos, las comunidades locales se han organizado para recuperar los derechos perdidos, como en el caso de Tárcoles en Costa Rica mencionado anteriormente, y luego desarrollar sus propias estrategias de uso sostenible.

El caso de Santa Lucía (Estudio de caso 25.8) ilustra el camino a menudo difícil para el acuerdo y el uso sostenible de los recursos en un área declarada por el Gobierno, mientras que el caso de la isla de Corón (Estudio de caso 25.9) demuestra cómo los pueblos indígenas pueden organizarse contra usos no sostenibles externos para conservar sus TICCA.

\section{Uso de recursos y cambios globales}

En muchas partes del mundo, los impactos proyectados del cambio climático sobre las áreas protegidas obligarán a reconsiderar su papel en la conservación de la biodiversidad y el uso sostenible (Hunter y Heywood, 2011; véase también el Capítulo 17). Los límites políticos de las áreas protegidas son fijos, pero el paisaje biológico no lo es. El diseño de tales áreas necesitará un replanteamiento significativo, lo que tiene importantes implicaciones para la gestión y manejo de las áreas protegidas (Schliep et al., 2008).

A mediados de este siglo, se espera que el cambio global impulse un aumento en el número de refugiados por causas ambientales cercano a los doscientos millones (Myers, 1997). Los impactos de esto sobre la conservación y el uso de la biodiversidad podrían ser significativos, ya que estas personas migrarán a territorios que no tienen la capacidad de albergarlos o alimentarlos sin alteraciones a gran escala. Esto también conducirá a un aumento en los incidentes conflictivos entre los usuarios de los recursos. Por su propia naturaleza, las personas desplazadas dependen en gran medida de su entorno para obtener alimentos, leña y otras necesidades de subsistencia, lo que suele conducir a la degradación o pérdida de bosques y otros recursos (Hunter y Heywood, 2011).

En estos contextos, lograr la conservación y el uso sostenible de los recursos requerirá un cambio de paradigma en la forma en que abordamos la gestión, el diseño y la conectividad de las áreas protegidas, y necesitaremos alianzas más efectivas entre las administraciones de áreas protegidas, los departamentos forestales y agrícolas que trabajen a través de agroecosistemas tradicionales, y los movimientos sociales e indígenas (Perfecto et al., 2009; Padulosi et al., 2011).

\section{Desarrollo y áreas protegidas}

A menudo, los proyectos a gran escala que hacen parte del crecimiento económico nacional o subnacional, así como las estrategias de desarrollo, pueden estar dentro o adyacentes a un área protegida. Estos incluyen, entre otros, la minería y otras formas de extracción; los proyectos de hidroelectricidad e irrigación; las carreteras y autopistas; los puertos; las instalaciones deportivas y turísticas; las líneas de comunicación y de transmisión de energía, y la expansión urbana. Muchos de estos proyectos representan serias amenazas para los ecosistemas, las especies y las poblaciones humanas dentro de las áreas protegidas. 


\section{Estudio de caso 25.9 Contrarrestar las amenazas externas en la isla de Corón, Filipinas}

Con frecuencia, las luchas de la comunidad para mantener o revivir el uso sostenible se han incorporado o han conducido a luchas políticas más amplias por los derechos y el control; este es especialmente el caso de muchos TICCA. El pueblo Tagbanwa de Filipinas, que habita la increíblemente bella isla de piedra caliza de Corón, estableció estrictas regulaciones de uso en su isla (Ferrari y de Vera, 2003) (véase la fotografía de la página del título, Capítulo 8). Los recursos forestales solo se utilizan para fines domésticos. Casi todos los lagos de agua dulce son sagrados. La entrada a esos lagos está estrictamente prohibida para todos, excepto para fines religiosos y culturales. El único lago accesible para un turismo altamente regulado es el lago Kayangan.

Hasta hace poco, los derechos territoriales de los Tagbanwa no tenían un reconocimiento legal, lo que llevó a la invasión de pescadores migrantes, operadores turísticos, políticos que buscaban acuerdos de tierras y agencias gubernamentales. Esto condujo al empobrecimiento de los ecosistemas y los recursos marinos.
A mediados de la década de 1980, los isleños se organizaron en la Fundación Tagbanwa de la isla de Corón (Tagbanwas Foundation of Coron Island, TFCl) e hicieron cabildeo para recuperar el control del manejo de sus recursos naturales. Primero solicitaron un Acuerdo Comunitario de Cuidado Forestal (Community Forest Stewardship Agreement, CFSA), el cual se otorgó en 1990 sobre las 7748 hectáreas de la isla de Corón y una isla vecina, Delian, pero no sobre las áreas marinas. Los Tagbanwa continuaron su lucha y en 1998 obtuvieron un Certificado de Reclamo de Dominio Ancestral por 22.284 hectáreas de tierras y aguas marinas. Finalmente, en 2001, después de delinear un mapa de alta calidad y un Plan de Manejo de Tierras Ancestrales, lograron obtener un Certificado de Título de Dominio Ancestral (Certificate of Ancestral Domain Title, CADT), el cual otorga derechos colectivos sobre la tierra.
Existen pocas evaluaciones nacionales o regionales sobre el nivel y los tipos de amenazas que el desarrollo plantea para las áreas protegidas. En India, la encuesta nacional de áreas protegidas (Kothari et al., 1989) encontró que el 62\% de las 293 áreas protegidas encuestadas tenían uno o más de los siguientes: carreteras, vías férreas, minería, represas, canales, industria o líneas de transmisión. Un estudio reciente de Kalpavriksh, una ONG de India, encontró que entre 1998 y 2009 cerca de trescientos proyectos que requerían el cambio de uso de tierras dentro de las áreas protegidas, solicitaron la aprobación ante la Junta Nacional para la Fauna Silvestre del Gobierno Central; aunque muchos quedaron pendientes de una decisión, de los que se abordaron, la mayoría fueron aprobados y pocos fueron rechazados (Menon et al., 2010). Curiosamente, casi todas las propuestas mineras fueron aprobadas, lo cual es difícil de entender dado que la minería es extremadamente dañina.

Uno de los problemas más debatidos en relación con el desarrollo de la infraestructura que afecta a las áreas protegidas en Europa Central es la construcción de carreteras y autopistas. Con frecuencia, las carreteras y las autopistas cruzan importantes hábitats o corredores de migración para especies protegidas, como los osos pardos (Ursus arctos), el lince euroasiático (Lynx lynx), los gatos monteses (Felis silvestris) y los lobos (Canis lupus). Find'o et al. (2007) descubrieron que la mayoría de las colisiones vehiculares con osos ocurrieron durante el período en que estos requieren altos niveles de alimentos nutritivos, desde mediados de julio hasta la hibernación entre noviembre y diciembre, cuando cubren grandes áreas atravesadas por carreteras. El resultado es que se presentan muchas colisiones vehiculares con osos den- tro y fuera de las áreas protegidas. Este es un problema grave a nivel mundial, aunque hay avances recientes en el diseño de pasos superiores e inferiores que permiten un movimiento más libre de la fauna de un lado a otro (por ejemplo, véase Locke, 2010).

Durante la mayor parte del siglo pasado, la deforestación en Latinoamérica se debió a la expansión de la agricultura. No obstante, en los últimos años se ha producido una mayor deforestación debido principalmente a las agencias corporativas y sus actividades. Con el aumento en la intensidad de los patrones de consumo debido a la globalización, existe una mayor presión sobre las áreas protegidas para la producción de biocombustibles y soja, energía (geotérmica e hidroeléctrica), minería y petróleo. Actualmente, muchos países enfrentan enormes amenazas por parte de los gobiernos que intentan desafectar, reducir el tamaño o reducir la categoría de protección de las áreas protegidas (WWF, 2014). Por ejemplo, la producción de soja en Argentina, Paraguayy Brasil, y más recientementeen Bolivia, ha invadido cientos de miles de hectáreas de las áreas protegidas. Es posible que las plantaciones de aceite de palma para la producción de biocombustibles sean la principal causa de los cambios en el uso de la tierra en Asia tropical, incluso dentro de áreas protegidas gubernamentales y en muchas tierras indígenas y comunitarias que podrían conformar TICCA (Campbell et al., 2008).

En otros lugares también están bajo amenaza los TICCA y otras áreas cruciales para la conservación. Debido a la construcción de varias represas hidroeléctricas en el río BioBio en Chile, los grupos indígenas Mapuche-Pehuenche libran una batalla legal contra el 


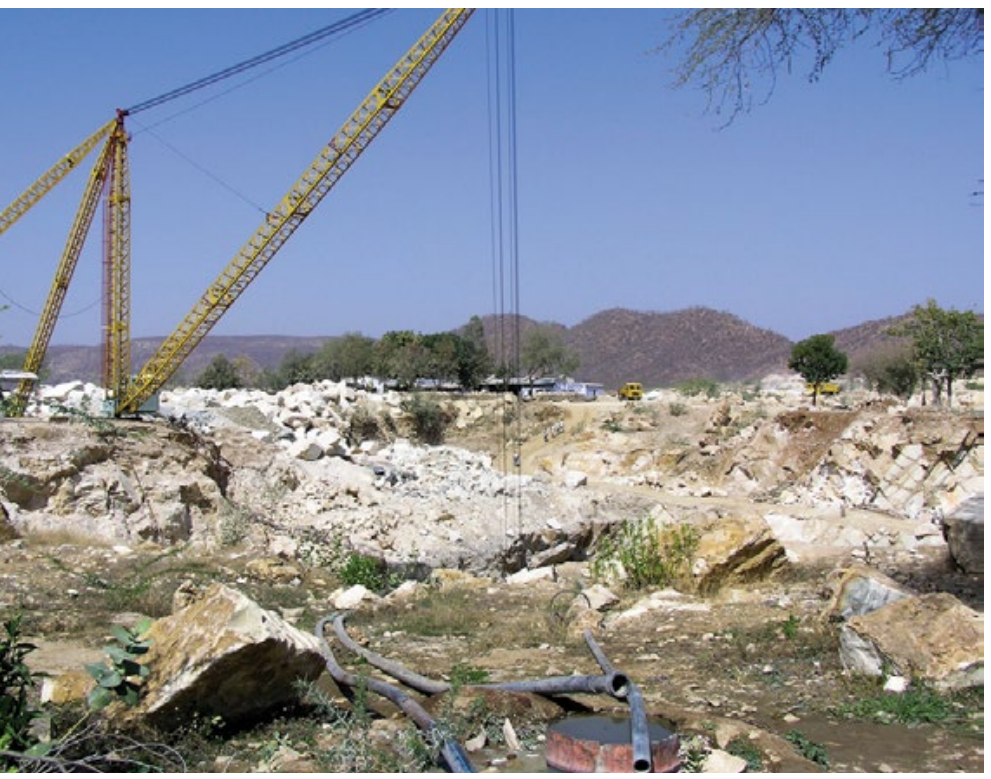

Minería dentro de la Reserva de Tigres Sariska, India

Fuente: Ashish Kothari

La naturaleza de los procesos y hallazgos de las EIAS, así como la naturaleza legalmente procesable de la legislación ambiental en términos de responsabilizar a los encargados de tomar decisiones estatales de las decisiones e impactos regulatorios ambientales, juegan un papel importante en los debates sobre el desarrollo de infraestructura en las principales áreas protegidas regionales. En los últimos años, el más notable de estos ha sido la propuesta del gobierno de Tanzania de construir una carretera en la parte norte del Parque Nacional Serengueti para unir diferentes áreas urbanas en esa zona del país. Los biólogos expresaron su preocupación de que una carretera de este tipo podría conducir a un aumento sustancial de la mortalidad durante la migración anual norte-sur de los ñus entre las llanuras del Serengueti y la Reserva Nacional Maasai Mara al norte de Kenia (Dobson et al., 2010; Norwegian University of Science and Technology, 2013). Se propusieron varios diseños de compromiso para una carretera que uniera las grandes poblaciones humanas del lago Victoria con los centros urbanos del este y se encargaron EIAS adicionales; en 2014, el diseño final de esta carretera aún era incierto. En Kenia, en la década de 2010 tuvo lugar un debate similar, aunque más limitado en términos espaciales, alrededor de una nueva carretera circunvalar en Nairobi que habría invadido los límites del Parque Nacional Nairobi, el cual se encuentra adyacente a la capital de la nación. Recientemente, esta carretera fue cuestionada con éxito en los tribunales y ahora su diseño y construcción definitivos son inciertos (Koross, 2013).

$\mathrm{Al}$ sur de Tanzania se desarrolló una nueva e importante mina de uranio en terrenos que fueron recientemente recortados de la Reserva de Caza Selous (Tairo, 2014).
La reserva Selous es un sitio patrimonio mundial, donde no se permite la minería, por lo que el recorte primero tuvo que ser aprobado por el Comité del patrimonio mundial de la UNESCO. No obstante, cuando entran en juego intereses comerciales o de infraestructura, dichos procesos plantean la posibilidad de que puedan desafectarse otras áreas protegidas, incluso aquellas con un alto nivel de reconocimiento internacional (véase el Estudio de caso 25.2).

En un contexto global, hay poco equilibrio entre el desarrollo y la conservación. En términos más generales, el contexto mundial de crecimiento económico, el aumento en los niveles de consumo, la globalización económica y financiera, el cambio climático y otros factores similares están teniendo un grave impacto en varios ecosistemas. La Evaluación de Ecosistemas del Milenio, la cual se centra en los cambios ecosistémicos que se han producido a escala global en los últimos cincuenta ańos, prevé que las consecuencias perjudiciales de la degradación de la Tierra pueden empeorar en los próximos cincuenta años (MEA, 2005). Advertencias similares pueden encontrarse en numerosas ediciones de la Perspectiva Mundial sobre la Diversidad Biológica (CBD, 2010).

La sostenibilidad a largo plazo de las áreas protegidas y de los esfuerzos de conservación dependerá de que se establezcan intervenciones y mecanismos institucionales eficaces para abordar mejor las verdaderas causas de la pérdida de biodiversidad. Por lo general, las autoridades del área protegida solo son responsables de la gestión y manejo dentro de las reservas, aunque la mayoría de las amenazas provienen de afuera de los límites de las áreas protegidas. Esto exige que los administradores de áreas protegidas trabajen con otras agencias y el sector privado para garantizar que las consideraciones de integridad y conservación del parque se integren en la planeación local y regional. En algunos casos, una sola agencia puede ser responsable tanto de la gestión de áreas protegidas como de la planeación del desarrollo sectorial -por ejemplo, en Madagascar, la Asociación Nacional de Gestión de Áreas Protegidas (Association National de Gestion des Aires Protégées, ANGAP) es responsable del turismo y de las áreas protegidas, pero esta es una excepción y no la regla. Los gobiernos locales pueden ser aliados valiosos para garantizar que la planeación del desarrollo complemente los objetivos de las áreas protegidas. Garantizar esta cooperación requiere no solo buenas relaciones personales, sino también un fuerte apoyo y coordinación a nivel estatal/provincial y entre los ministerios a nivel nacional. Es más probable que los gobiernos locales respalden la conservación cuando reconocen los beneficios que las áreas protegidas brindan al impulsar el crecimiento económico local (por ejemplo, el turismo en muchos países) 
o al mantener funciones ecosistémicas cruciales como el suministro de agua (por ejemplo, el Parque Nacional Chingaza en Colombia, la fuente de agua para Bogotá, su capital; véase Parques Nacionales Naturales de Colombia, 2008).

Uno de los pocos intentos de abordar esto sistemáticamente y a nivel mundial es la incidencia de la UICN para salvaguardar ciertas categorías de áreas protegidas. Por ejemplo, en el segundo Congreso Mundial de la Conservación de la UICN (en Amman, Jordania, en 2000), los miembros adoptaron la Recomendación 2.82 (Protección y conservación de la diversidad biológica de las áreas protegidas de cara a los efectos negativos de la exploración y extracción minera). Esta recomendación:

1. Pide que los Estados miembros de la UICN prohíban la exploración y extracción minera en áreas protegidas de las categorías I-IV.

2. Recomienda controles estrictos sobre tales actividades en áreas protegidas de las categorías V y VI.

3. Insta a que cualquier cambio en los límites de las áreas protegidas para acomodar las actividades mineras se rija por estándares estrictos.

4. Recomienda evaluaciones del impacto ambiental para garantizar que las actividades mineras fuera de las áreas protegidas no tengan un impacto negativo en ellas.

Si bien esto no fue ampliamente aceptado, en 2003 la UICN y la UNESCO lograron convencer al Consejo Internacional de Minería y Metales (Council on Mining and Minerals, ICMM) de una moratoria voluntaria sobre la minería en sitios patrimonio mundial (ICMM, 2003). Pero esto deja fuera muchas áreas protegidas que tienen una gran importancia para la conservación; la moratoria solo es voluntaria y es susceptible de violación en varios países con una gobernanza ambiental débil; el ICMM no incluye muchas compañías mineras, y posiblemente lo más importante, las áreas protegidas que no están formalmente reconocidas -así la mayoría de los TICCA y las APP, como se señaló anteriormente y en el Capítulo 7- no reciben protección de la misma. Los críticos de la minería alegan que el acuerdo es solamente un "lavado de imagen verde", ya que la industria paga poco o ningún costo, pero gana credibilidad. Además, es frecuente que algunos gobiernos estén dispuestos a recortar tierras de las áreas protegidas para permitir tales actividades (como el ejemplo de la reserva Selous mencionado anteriormente). En muchas partes del mundo, los nuevos desarrollos en la exploración petrolera, incluida la fractura hidráulica, amenazan con dañar aún más los ecosistemas naturales.

\section{Conclusión}

Vale la pena mencionar algunas observaciones finales para los dos aspectos tratados en este capítulo: el uso de los recursos y los proyectos de desarrollo.

El uso de los recursos puede contribuir de varias maneras al logro de los objetivos de conservación, en términos ecológicos (por ejemplo, cuando los valores de la biodiversidad se mantienen mediante el uso), en términos económicos (por ejemplo, cuando permitir el uso sostenible genera ingresos para la gestión del parque) y en términos sociales (por ejemplo, cuando permitir el uso local sostenible genera o mantiene el apoyo local y el "compromiso" con la conservación). Las políticas y prácticas de conservación deben ser flexibles para acomodar el uso de los recursos que las comunidades locales realizan, especialmente aquellos que son cruciales para la supervivencia y los medios de subsistencia, cuando son o pueden llegar a ser compatibles con los objetivos de conservación (asumiendo que estos objetivos se establecieron de manera democrática y se basan en los mejores conocimientos disponibles y los principios y prácticas de "buena gobernanza" descritos en el Capítulo 7). En el caso de los TICCA, y hasta cierto punto en las áreas protegidas cogestionadas, esto suele ocurrir de manera natural, pero puede requerir una atención especial en muchas áreas protegidas manejadas por el Gobierno.

En muchos casos, cuando tal uso de los recursos no es compatible con los objetivos de conservación, se han tomado medidas para imponer restricciones y la provisión o la facilitación simultánea de alternativas (por ejemplo, en el Parque Nacional Kibale; véase el Estudio de caso 25.4). Sin embargo, no siempre estas alternativas compensan adecuadamente las pérdidas (como en el caso del Gran Parque Nacional de Himalaya; Estudio de caso 25.2), o pueden ser culturalmente inapropiadas y económicamente inviables. Como se discutió anteriormente, tales deficiencias son una lección clave de las iniciativas de los ICDP en varias partes del mundo, y deben considerarse de manera especial en la planeación de la gestión y manejo de áreas protegidas.

Es importante tener en cuenta que cada situación es única; lo que funciona perfectamente para que el uso de los recursos sea sostenible en un sitio puede no funcionar en otro. Entre los sitios y las situaciones pueden establecerse algunos puntos en común, y entre los diferentes sitios pueden existir lecciones aprendidas, pero para cada sitio y situación se necesitan nuevas evaluaciones, estudios y monitoreos basados en el conocimiento local y externo. Para que toda la comunidad participe de manera eficaz en la conservación es importante que se resuelvan los conflictos inter e 
intracomunitarios, especialmente los relacionados con la tenencia y la propiedad de la tierra, el acceso a los recursos y la distribución de los beneficios de tales usos.

La seguridad de la tenencia, los derechos territoriales, los derechos sobre los recursos, el derecho a participar en la toma de decisiones y las responsabilidades concomitantes con la conservación y el prójimo se consideran cada vez más cruciales, no solo para la participación de las poblaciones locales en todos los tipos de gobernanza de las áreas protegidas, sino también para aclarar las funciones y responsabilidades de las agencias gubernamentales en el caso de las áreas protegidas manejadas por el Gobierno (véase el Capítulo 7).

La gestión eficaz de los recursos debe basarse en una buena información, la cual puede derivarse de métodos científicos modernos o estar integrada en la ciencia, el conocimiento y las prácticas culturales indígenas y tradicionales. El conocimiento indígena/tradicional y local puede ser de importancia central en el mapeo de hábitats y áreas de uso de recursos y en el establecimiento de zonas de uso de recursos que sean viables y socialmente aceptables.

Es importante incorporar estrategias para lidiar con diferentes tipos de falta de privilegios sociales y económicos, incluidos las desigualdades de género, las desigualdades y los prejuicios étnicos, la captura de beneficios por parte de la élite y otros factores que podrían distorsionar la distribución equitativa de las capacidades y poderes sobre la toma de decisiones y de los beneficios de conservación.

Pueden aprenderse lecciones de varios tipos de gobernanza - por ejemplo, muchos TICCA han ideado modos adaptativos y procesos institucionales para determinar niveles y tipos de uso de recursos que no pongan en peligro los ecosistemas ni las especies relevantes, de los cuales el Gobierno y otros pueden aprender. Muchas áreas protegidas manejadas por el Gobierno han desarrollado sistemas robustos de planeación de la gestión y el manejo, de los cuales los TICCA podrían aprender. A nivel nacional y subnacional, deben crearse plataformas para compartir y aprender.

Es probable que factores globales actuales y potenciales como el cambio climático, alteren la situación respecto al uso de los recursos en el interior y alrededor de las áreas protegidas. Para lograr una adaptación a tales cambios, no solo se necesitará una considerable resiliencia y flexibilidad, sino también una conectividad a lo largo de los grandes paisajes terrestres y marinos, y la colaboración entre varios titulares de derechos y partes interesadas.

Los proyectos de desarrollo e infraestructura que tengan un impacto sobre las áreas protegidas y otros sitios de conservación deben pasar por procesos de tamizaje y toma de decisiones basados en la Democracia y el conocimiento, en los que las autoridades del área protegida y las poblaciones locales deben tener una voz central. Idealmente, las políticas nacionales deben designar sitios que sean cruciales para la conservación ecológica y de la biodiversidad como áreas restringidas donde no se permitan actividades a gran escala que tengan un impacto perjudicial; esto también debería aplicarse a las "cuencas de captación" o "zonas de impacto" fuera del área protegida donde tales actividades puedan tener un impacto sobre la misma.

Si bien tales medidas, o los esfuerzos más globales como la presión de la UICN para que ciertas categorías de áreas protegidas quedan fuera del alcance de la minería, son pasos para limitar los impactos adversos del desarrollo sobre estas áreas, también hay un enfoque creciente sobre la necesidad de reorientar el marco del desarrollo. Sin esto, el daño ecológico generalizado causado por la industria extractiva, la infraestructura y otros procesos de "desarrollo", que son inherentes a un modelo que coloca al crecimiento económico por encima de todo, seguirán socavando la biodiversidad y las comunidades, especialmente las más dependientes del entorno natural. Una de las líneas de dicha reorientación es tomar el camino del "desarrollo sostenible", en el que los impactos ambientales se integran más centralmente en la planeación del desarrollo y la economía se mueve hacia procesos, tecnologías, responsabilidades y otras medidas más ecológicas. Este es el énfasis de la declaración de resultados de la Conferencia de las Naciones Unidas sobre el Desarrollo Sostenible Río + 20 (UNCSD, 2012) y de las negociaciones en curso para una agenda post-2015 que reemplace los Objetivos de Desarrollo del Milenio (Sustainable Development Knowledge Platform, 2014). Otra tendencia sostiene que esto será inadecuado ya que el desarrollo todavía depende del crecimiento económico, que es imposible de mantener en un mundo con límites ecológicos. Por lo tanto, esto hace un llamado a un cambio fundamental hacia estrategias e indicadores del bienestar humano que no se basen en el crecimiento, y que no solo estén en sintonía con los límites de la naturaleza, sino también que sean más acordes con que todos tengan un acceso directo a las necesidades básicas (agua, alimentos, vivienda, saneamiento, vestimenta, aprendizaje, salud, relaciones sociales, etc.) (Rijnhout et al., 2014). Este capítulo no es el lugar para abordar estos temas con más detalle, pero los administradores de áreas protegidas, los titulares de derechos, las partes interesadas y todos los interesados en la conservación deberán comprometerse de una forma $\mathrm{u}$ otra con este contexto más amplio de las vías de desarrollo y bienestar. 


\section{Referencias}

Lecturas recomendadas

Adams, W.M. (2004). Against Extinction: The story of conservation. Londres: Earthscan.

Alers, M.; Bovarnick, A.; Boyle, T.; Mackinnon, K. y Sobrevila, C. (2007). Reducing Threats to Protected Areas: Lessons from the field. Nueva York: The World Bank and United Nations Development Programme.

Amazon Conservation Association. (2013). Amazon Conservation Association. Recuperado de: www. amazonconservation.org/ourwork/livelihoods.html

Amend, S. y Amend, T. (1995). National Parks without People? The South American experience. Quito: IUCN y Parques Nacionales y Conservacion Ambiental.

Amend, T.; Brown, J.; Kothari, A.; Phillips, A. y Stolton, S. (eds.). (2008). Protected Landscapes and Agrobiodiversity Values. Values of Protected Landscapes and Seascape, vol. 1. Heidelberg, Alemania: IUCN y GTZ, Kasparek Verlag.

Anderson, D. y Grove, R.H. (eds.). (1987). Conservation in Africa: Peoples, policies and practice. Cambridge: Cambridge University Press.

Argumedo, A. (2008). The Potato Park, Peru: conserving agrobiodiversity in an indigenous biocultural heritage area. En: T. Amend, J. Brown, Kothari, A. Phillips y S. Stolton (eds.). Protected Landscapes and Agrobiodiversity Values. Values of Protected Landscapes and Seascape, vol. 1, pp. 45-58. Heidelberg, Alemania: IUCN y GTZ, Kasparek Verlag.

Arshad, M. y Khalid, U. (2008). Ungulate population estimate of Torghar, Pakistan. [Manuscrito inédito].

Australian Committee for IUCN. (1999). Great Barrier Reef World Heritage Area: Condition, management and threats. Sídney: Australian Committee for IUCN.

Bassi, M. y Tache, B. (2011). The community conserved landscape of the Borana Oromo, Ethiopia: opportunities and problems. Management of Environmental Quality: An International Journal, 22(2), 174-186.
Bassols Isamat, E.; Perramon Ramos, B.; Mallarach Carrera, J.M. y Falgarona Bosch, J. (2011). The conservation of the agrobiodiversity of La Garrotxa Volcanic Zone Natural Park. Management of Environmental Quality: An International Journal, 22(2), 233-249. Recuperado de: www.emeraldinsight. com/journals. htm? issn=1477-7835yvolume $=22$ yissue $=2 y P H P S E S S I D=$ gnubmq $2 \mathrm{ks} 8 \mathrm{~b} 72 \mathrm{aepclq} l \mathrm{ldg} 7 \mathrm{v} 2$

Battharai, B.; Ojha, H.; Ram Banjade, M. y Luintel, H. (2003). Effect of NTFP Market Expansion on Sustainable Local Livelihoods. Nepal: Forest Resource Action Team.

Baviskar, A. (2003). States, communities and conservation: the practice of ecodevelopment in the Great Himalayan National Park. En: V. Saberwal y M. Rangarajan (eds.). Battles over Nature: Science and the politics of conservation. Nueva Delhi: Permanent Black.

Bélair, C.; Ichikawa, K.; Wong, B.Y.L. y Mulongoy, K.J. (eds.). (2010). Sustainable use of biological diversity in socio-ecological production landscapes. Background to the Satoyama Initiative for the benefit of biodiversity and human well-being, Technical Series No. 52. Montreal: Secretariat of the Convention on Biological Diversity.

Berkes, F. (1989). Common Property Resources: Ecology and community-based sustainable development. Londres: Belhaven Press.

Bertzky, B.; Corrigan, C.; Kemsey, J.; Kenney, S.; Ravilious, C.; Besançon, C. y Burgess, N. (2012). Protected Planet Report 2012: Tracking progress towards global targets for protected areas. Gland: IUCN y Cambridge: UNEP-WCMC.

Bezaury-Creel, J. y Gutiérrez Carbonell, D. (2009). Áreas naturales protegidas y desarrollo social en México, en Capital natural de México. Volume II: Estado de conservación y tendencias de cambio. México: Conabio.

Bird, R.B.; Tayor, N.; Codding, B.F. y Bird, D.W. (2013). Niche construction and Dreaming logic: Aboriginal patch mosaic burning and varanid lizards (Varanus gouldii) in Australia. Proceedings of the Royal Society B: Biological Sciences, 280(1772), 20132297.

Bolen, E.G. y Robinson, W.L. (2003). Wildlife Ecology and Management, $5^{\mathrm{a}}$ ed. San Francisco: Pearson Benjamin Cummings. 
Borrini-Feyerabend, G.; Kothari, A. y Oviedo, G. (2004). Indigenous and Local Communities and Protected Areas: Towards equity and enhanced conservation, IUCN WCPA Best Practice Series No. 11. Cambridge: IUCN.

(2010). Strengthening what works: recognizing and supporting the conservation achievements of indigenous peoples and local communities, Briefing Note No. 10. Gland: IUCN WCPA- CEESP TILCEPA, ICCA Consortium, CEESP TGER, GEF SGP, WAMIP, Cenesta y GTZ.

Brandon, K.; Redford, K.H. y Sanderson, S.E. (eds.). (1998). Parks in Peril: People, politics and protected areas. Washington D.C.: The Nature Conservancy and Island Press.

Brown, J. y Kothari, A. (2011). Traditional and agricultural landscapes and community conserved areas: an overview. Management of Environmental Quality: An International Journal, 22(2), 139-153.

BurrenLIFE. (2014). The BurrenLIFE Project. Carron, Irlanda. Recuperado de: www.burrenlife.com/

Cadman, M.; Petersen, C.; Driver, A.; Sekhran, N.; Maze, K. y Munzhedzi, S. (2010). Biodiversity for Development: South Africa's landscape approach to conserving biodiversity and promoting ecosystem resilience. Pretoria, Sudáfrica: South African National Biodiversity Institute. Recuperado de: www.undp. org/content/undp/en/home/librarypage/environment-energy/ecosystems_and_biodiversity/biodiversity_fordevelopment/

Cairns, M.F. (2014). Shifting Cultivation and Environmental Change: Indigenous people, agriculture and forest conservation. Oxford: Routledge.

Campbell, A.; Kapos, V.; Lysenko, I.; Scharlemann, J.P.W.; Dickson B.; Gibbs H.K.; Hansen, M. y Miles, L. (2008). Carbon Emissions from Forest Loss in Protected Areas. Cambridge: UNEP World Conservation Monitoring Centre.

Campbell, L.; Haalboom, B. y Trow, J. (2007). Sustainability of community-based conservation: sea turtle egg harvesting in Ostional (Costa Rica) ten years later. Environmental Conservation, 34(2), 122-131.

Chamberlain, J.L.; Cunningham, A.B. y Nasi, R. (2004). Diversity in forest management: non-timber forest products and bush meat. Renewable Resources Journal (verano), 11-19.
Charles, A. (2011). Human rights and fishery rights in small-scale fisheries management. En: R.S. Pomeroy y N.L. Andrew (eds.). Small-Scale Fisheries Management: Frameworks and approaches for the developing world, pp. 59-74. Wallingford, Reino Unido: CAB International.

Wilson, L. (2009). Human dimensions of marine protected areas. ICES Journal of Marine Science, 66, 6-15.

Chhatre, A. y Agrawal, A. (2009). Trade-offs and synergies between carbon storage and livelihood benefits from forest commons. Proceedings of the National Academy of Sciences, 106(42), 17.667-17.670. Doi:10.1073/pnas.0905308106

Saberwal, V. K. (2006). Democratizing Nature: Politics, conservation and development in India. Nueva Delhi: Oxford University Press.

Chhetri, P.; Mugisha, A. y White, S. (2003). Community resources use in Kibale and Mt Elgon National Parks, Uganda. Parks, 13, 28-49.

DD Child, B. (ed.). (2004). Parks in Transition: Biodiversity, rural development, and the bottom line. Londres: Earthscan.

Compton, J. y Le, Q.H. (1998). Borderline: An assessment of wildlife trade in Vietnam. Hanoi. WWF Indochina Programme.

Convention on Biological Diversity (CBD). (2004). Addis Ababa Principles and Guidelines. Montreal: Convention on Global Biodiversity Secretariat. Recuperado de: www.cbd.int/sustainable/addis.shtml

(2010). Global Biodiversity Outlook. Montreal: Convention on Global Biodiversity Secretariat. Recuperado de: www.cbd.int/gbo/

Convention on International Trade in Endangered Species of Wild Fauna and Flora (CITES). (2000). Bushmeat as a trade and wildlife management issue, CoP11 Doc. 11.44. Eleventh Meeting of the Conference of the Parties, abril 10-20. Gigiri, Kenya. Recuperado de: www.cites.org/eng/cop/11/doc/44.pdf

(2013). Status of African elephant populations and levels of illegal killing and the illegal trade in ivory: a report to the African Elephant Summit, December 2013. Ginebra: CITES Secretariat, IUCN/SSC African Elephant Specialist Group y TRAFFIC International. 
Danielsen, F.; Jensen, A.E.; Alviola, P.A.; Balete, D.S.; Mendoza, M.; Tagtag, A.; Cistodio, C. y Enghoff, M. (2005). Does monitoring matter? A quantitative assessment of management decisions from locallybased monitoring of protected areas. Biodiversity and Conservation, 14, 2633-2652.

Das, P. (2007). The politics of participatory conservation - the case of Kailadevi Wildlife Sanctuary, Rajasthan. En: G. Shahabuddin y M. Rangarajan (eds.). Making Conservation Work, pp. 113-46. Nueva Delhi: Permanent Black.

De Beer, F. (2013, octubre 4). Community-based natural resource management: living with Alice in Wonderland? Community Development Journal 48, 555-570. Recuperado de: journals.ohiolink.edu/ ejc/article.cgi?issn $=00103802$ yissue $=v 48 i 0004 y$ article $=555$ _cnrmlwaiw

Desor, S. (2013). Citizens report 2013 on community forest rights under Forest Rights Act. Pune, India: Kalpavriksh; Bhubaneshwar, India: Vasundhara, Oxfam India, Delhi, en nombre de Community Forest Rights Learning and Advocacy Process.

Dobson, A.P.; Borner, M.; Sinclair, A.R.E.; Hudson, P.J.; Anderson, T.M.; Bigurube, G. y Davenport, T.B.B. (2010). Road will ruin Serengeti. Nature, 467(7313), 272-273.

Dowie, M. (2009). Conservation Refugees: The hundredyear conflict between global conservation and native peoples. Cambridge, Estados Unidos: MIT Press.

Drew, J.A. (2005). Use of traditional ecological knowledge in marine conservation. Conservation Biology, 19(4), 1286-1293.

Dudley, N. (ed.). (2008). Guidelines for Applying Protected Area Management Categories. Gland: IUCN.

Evans, S. (1999). The Green Republic: A conservation history of Costa Rica. Austin: University of Texas Press.

Failing, L.; Gregory, R. y Harstone, M. (2007). Integrating science and local knowledge in environmental risk management: a decision-focused approach. Ecological Economics, 64, 47-60.

FairWild. (2009). FairWild Foundation. Cambridge y Zurich. www.fairwild.org/

Farvar, M.T. (2003). Myths, challenges and questions on mobile pastoralism in West Asia. Policy Matters, $12,31-41$.
Ferrari, M.F. y de Vera, D. (2003). A "participatory" or a "rights-based" approach? Which is best for protected areas and indigenous peoples in the Philippines? Policy Matters, 12, 166-170.

Fin'o, S.; Skuban, M. y Koreň, M. (2007). Brown Bear Corridors in Slovakia. Eslovaquia: Carpathian Wildlife Society.

Food and Agriculture Organization (FAO). (2010). Second Report on the State of the Worlds Plant Genetic Resources for Food and Agriculture. Roma: Food and Agriculture Organization.

(2012). The State of World Fisheries and Aquaculture. Roma: Food and Agriculture Organization.

Fonseca, A. (2009). Decimosexto Informe Estado de la Nación en Desarrollo Sostenible. Informe Final. Estado de la Nación en la zona marino costera. San José, Costa Rica: Proyecto Estado de La Nación Costa Rica.

Friedlander, A.; Sladek Nowlis, J.; Sanchez, J.A.; Appeldoorn, R.; Usseglio, P.; McCormick, C.; Bejarano, S. y Mitchell-Chui, A. (2003). Designing effective marine protected areas in Seaflower Biosphere Reserve, Colombia, based on biological and sociological information. Conservation Biology, 17(6), 1769-1784.

Frisina, M.R. (2000). Suleiman markhor (Capra falconeri jerdoni) and Afghan urial (Ovis orientalis cycloceros) population status in the Torghar Hills, Balochistan Province, Pakistan. [Reporte inédito para Society for Torghar Environmental Protection and the United States Fish and Wildlife Service].

Tareen, S.N.A. (2009). Exploitation prevents extinction: case study of endangered Himalayan sheep and goats. En: B. Dickson, J. Hutton y B. Adams (eds.). Recreational Hunting, Conservation and Rural Livelihoods: Science and practice, pp. 141-156. Oxford: Wiley-Blackwell.

Galland, P. (2013). Appraisal Report: Retezat National Park with extension to Piatra Craiului (Romania). Convention on the Conservation of European Wildlife and Natural Habitats, T-PVS/DE (2013) 3. Council of Europe. Recuperado de: wcd.coe.int/ ViewDoc.jsp?id=2042185ySite=

Galvin, M. y Haller, T. (2008). People, Protected Areas and Global Change: Participatory conservation in Latin America, Africa, Asia and Europe. Berna, Suiza: University of Bern, NCCR North-South. 
Gell, F.R. y Roberts, C.M. (2002). The Fishery Effects of Marine Reserves and Fishery Closures. Washington D.C.: WWF.

Geoghegan, T. y Renard, Y. (2002). Beyond community involvement: lessons from the insular Caribbean, Parks (Special Issue on Local Communities and Protected Areas), 12(2), 16-26.

Gibson, C.C. (1999). Politicians and Poachers: The political economy of wildlife policy in Africa. Cambridge: Cambridge University Press.

Govan, H. (ed.). (2009). Status and Potential of Locally Managed Marine Areas in the South Pacific: Meeting nature conservation and sustainable livelihood targets through widespread implementation of LMMAs. Numea, Nueva Caledonia: Initiative for the Protection and $\mathrm{Ma}-$ nagement of Coral Reefs in the Pacific. Recuperado de: SPREP/WWF/WorldFish-Reefbase/CRISP.

Jupiter, S. y Comley, J. (2012). Recognition and support of ICCAs in Fiji. En: A. Kothari, with C. Corrigan, H. Jonas, A. Neumann y H. Shrumm (eds.). Recognizing and Supporting Territories and Areas Conserved by Indigenous Peoples and Local Communities: Global overview and national case studies, pp. 138-913, CBD Technical Series No. 64. Montreal: Secretariat of the Convention on Biological Diversity, ICCA Consortium, Kalpavriksh y Natural Justice.

Graves, A. (2004). Mapping Subsistence Agriculture in the National Park of American Samoa. National Park Service. Washington D.C.: US Department of the Interior. Recuperado de: www.nps.gov/gis/mapbook/tech/30.html

Gubbi, S.; Linkie, M. y Leader-Williams, N. (2008). Evaluating the legacy of an integrated conservation and development project around a tiger reserve in India. Environmental Conservation, 35, 331-339. Doi: $10.1017 /$ S0376892908005225

Gugić, G. (2009). Managing Sustainability in Conditions of Change and Unpredictability: The living landscape and floodplain ecosystem of the Central Sava River Basin. Krapje, Croatia: Lonjsko Polje Nature Park Public Service.

Hackel, J.D. (1999). Community conservation and the future of Africa's wildlife. Conservation Biology, 13, 726-734.
Harper, S.; Zeller, D.; Hauzer, M.; Pauly, D. y Sumaila, R.U. (2013). Women and fisheries: contribution to food security and local economies. Marine Policy, 39, 56-63. Doi:10.1016/j.marpol.2012.10.018

Hayes, T.M. (2006). Parks, people, and forest protection: an institutional assessment of the effectiveness of protected areas. World Development, 34(12), 2064-2075.

Heywood, V.H. (1999). Trends in agricultural biodiversity. En: J. Janick (ed.). Perspectives on New Crops and New Uses, pp. 2-14. Alexandria, Estados Unidos: ASHS Press.

Homewood, K.M. y Rodgers, W.L. (1991). Maasailand Ecology: Pastoralist development and wildlife conservation in Ngorongoro, Tanzania. Cambridge: Cambridge University Press.

Hunter, D. y Heywood, V.H. (2011). Crop Wild Relatives: A manual of in situ conservation. Londres: Earthscan.

Infield, M. (2003). National parks as cultural entities. Policy Matters, 13, 64-70.

International Council on Mining and Metals (ICMM). (2003). ICMM Position Statement on Mining and Protected Areas, Londres: International Council on Mining and Metals. Recuperado de: www.icmm. com/publications/497ICMMPositionStatementonMiningandProtectedAreas.pdf

International Union for Conservation of Nature (IUCN). (2000). IUCN Policy Statement on Sustainable Use of Wild Living Resources, Resolution 2.29, First World Conservation Congress. Gland: IUCN.

(2004). Themesheet I6: Octopus and sea cucumber fisheries. En: Managing Marine Protected Areas: A toolkit for the Western Indian Ocean. Nairobi: IUCN Eastern African Regional Programme. Recuperado de: wiomsa.org/mpatoolkit/Themesheets/I6_Octupus_and_sea_cucumber_fisheries.pdf

United Nations Environment Programme (UNEP) y World Wildlife Fund (WWF). (1980). World Conservation Strategy: Living resource conservation for sustainable development. Gland: IUCN y WWF y Nairobi: UNEP.

Jan, A. (1992). Review and Analysis of Forest Polices of Pakistan. Islamabad: Government of Pakistan.

Kamboj, V.P. (2000). Herbal medicine. Current Science, 78(1), 35-39. 
Kathe, W. (2011). The new FairWild standard - a tool to ensure sustainable wild-collection of plants. $\mathrm{Me}$ dicinal Plant Conservation, 14, 14-17.

Pätzold, B.; Leaman, D.; Timoshyna, A.; Newton, D.; Khou, E.; Kinhal, G.; Sapkota, I.B.; Pasha, M.K.S.; Ndam, N.; Melisch, R.; Bundalo, S.; Honnef, S.; Osborn, T.; Buitrón, X. y Liu, X. (2010). Wild for a Cure: Ground-truthing a standard for sustainable management of wild plants in the field. Cambridge: TRAFFIC International.

Koross, K. (2013, mayo 31). Bypass stopped from encroaching on Nairobi National Park. The Star (Nairobi). Recuperado de: www.the-star.co.ke/news/ article-122527/bypass-stopped-encroaching-nairobi-national-park

Kothari, A. (2010, marzo 7). The birds are back. The Hindu Sunday Magazine. Recuperado de: hindu.com/thehindu/mag/2010/03/07/stories $/ 2010030750400700 . h t m$

Pathak, N. (2005). Tragopans and tribals: a Naga transformation. Sanctuary Asia, 25(5), 60-63.

Corrigan, C.; Jonas, H.; Neumann, A. y Shrumm, H. (eds.). (2012). Recognizing and Supporting Territories and Areas Conserved by Indigenous Peoples and Local Communities: Global overview and national case studies, CBD Technical Series No. 64. Montreal: Secretariat of the Convention on Biological Diversity, ICCA Consortium, Kalpavriksh y Natural Justice.

Pande, P.; Singh, S. y Variava, D. (1989). Management of National Parks and Sanctuaries in India: A status report. Nueva Delhi: Indian Institute of Public Administration.

Singh, N. y Suri, S. (1995, octubre 28). Conservation in India: a new direction. Economic and Political Weekly, 30(43), 2755-2766.

Lasgorceix, A. y Kothari, A. (2009, diciembre 5). Displacement and relocation of local communities from protected areas in India: a synthesis and analysis of case studies. Economic and Political Wee$k l y$, XLIV(49), 37-47.

Leader-Williams, N.; Baldus, R.D. y Smith, R.J. (2009). The influence of corruption on the conduct of recreational hunting. En: B. Dickson, J. Hutton y B. Adams (eds.). Recreational Hunting, Conservation and Rural Livelihoods, pp. 296-316. Oxford: Wiley-Blackwell.
Leida, R.; de Zoysa, U.; Kothari, A. y Healy, H. (2014). Towards a global agenda of sustainability and equity: civil society engagement for the future we want. UNEP Perspectives, 12. Recuperado de: www. unep.org/civil-society/Portals/24105/documents/ perspectives/ENVIRONMENT_PAPERS_DISCUSSION_12.pdf

Locke, H. (2010). Yellowstone to Yukon Connectivity Conservation Initiative. En: G.L. Worboys, W. Francis y M. Lockwood (eds.). Connectivity Conservation Management: A global guide. Londres: Earthscan.

Lockwood, M.; Worboys G.L. y Kothari, A. (2006). Managing Protected Areas: A global guide. Londres: Earthscan.

McNeely, J.A. (1998). Mobilizing Broader Support for Asia's Biodiversity: How civil society can contribute to protected area management. Manila: Asian Development Bank.

Miller, K.R.; Reid, W.V.; Mittermeier, R.A. y Werner, T.B. (1990). Conserving the Worlds Biodiversity. Washington D.C.: The World Bank y Gland: IUCN.

McShane, T.O. y Wells, M.P. (2004). Getting Biodiversity Projects to Work. Towards more effective conservation and development. Nueva York: Columbia University Press.

Madrigal Cordero, P. y Solís Rivera, V. (2012). Recognition and support of ICCAs in Costa Rica. En: A. Kothari, C. Corrigan, H. Jonas, A. Neumann y H. Shrumm (eds.). Recognising and Supporting Territories and Areas Conserved by Indigenous Peoples and Local Communities: Global overview and national case studies, pp. 127-129. CBD Technical Series No. 64. Montreal: Secretariat of the Convention on Biological Diversity, ICCA Consortium, Kalpavriksh y Natural Justice.

Margolius, R. y Salafsky, N. (2001). Is Our Project Succeeding? A guide to threat reduction assessment for conservation. Washington D.C.: Biodiversity Support Programme.

Martin, G.; Camacho Benavides, C.; del Campo García, C.; Fonseca, S.A.; Chapela Mendoza, F. y González Ortiz, M.A. (2011). Indigenous and community-conserved areas in Oaxaca, Mexico. Management of Environmental Quality: An International Journal, 22(2), 250-266. 
Menon, M.; Kohli, K. y Samdariya, V. (2010). Diversion of protected areas: role of the Wildlife Board. Economic and Political Weekly, XLV(26-27), 18-21.

Millennium Ecosystem Assessment (MEA). (2005). Millennium Ecosystem Assessment. Washington D.C.: Island Press. Recuperado de: www.maweb.org

Myers, N. (1997). Environmental refugees. Population and Environment, 19(2), 167-182.

Naqizadeh, N.; Abbas, D. y Farvar, T. (2012). Recognition and support of ICCAs in Iran. En: A. Kothari, with C. Corrigan, H. Jonas, A. Neumann y H. Shrumm (eds.). Recognizing and Supporting Territories and Areas Conserved by Indigenous Peoples and Local Communities: Global overview and national case studies, pp. 132-134, CBD Technical Series No. 64. Montreal: Secretariat of the Convention on Biological Diversity, ICCA Consortium, Kalpavriksh y Natural Justice.

Naidoo, R.; Weaver, L.C.; Stuart-Hill, G. y Tagg, J. (2011). Effect of biodiversity on economic benefits from communal lands in Namibia. Journal of Applied Ecology, 48(2), 310-316. Doi:10.1111/ j.1365-2664.2010.01955.x

Nasi, R.; Brown, D.; Wilkie, D.; Bennett, E.; Tutin, C.; van Tol, G. y Christophersen, T. (2008). Conservation and Use of Wildlife-Based Resources: The bushmeat crisis. CBD Technical Series 33. Montreal: Secretariat of the Convention on Biological Diversity y Bogor, Indonesia: Center for International Forestry Research.

Taber, A. y van Vliet, N. (2011). Empty forests, empty stomachs? Bushmeat and livelihoods in the Congo and Amazon Basins. International Forestry Review, 13(3), 355-368.

National Park Service (NPS). (2014). National Park of American Samoa: Laws and Policies. Recuperado de: www.nps.gov/npsa/parkmgmt/lawsandpolicies.htm

Parques Nacionales Naturales de Colombia. (2008). Parque Nacional Natural: Chingaza. Recuperado de: www. parquesnacionales.gov.co/PNN/portel/ libreria/php/decide.php?patron=02.02021202yf_patron $=02.020212$

Naughton-Treves, L.; Holland, M.B. y Brandon, K. (2005). The role of protected areas in conserving biodiversity and sustaining local livelihoods. Annual Review of Environment and Resources, 30, 219-252. Doi:10.1146/annurev.energy.30.050504.164507
Nelson, A. y Chomitz, K.M. (2011). Effectiveness of strict vs. multiple use protected areas in reducing tropical forest fires: a global analysis using matching methods. PLoS One, 6(8), e22722. Doi:10.1371/ journal.pone.0022722

(ed.). (2010). Community Rights, Conservation and Contested Land: The politics of natural resource governance in Africa. Londres: Earthscan.

(2012). Natural conservationists? Evaluating the impact of pastoralist land use practices on Tanzanias wildlife economy. Pastoralism, 2(1), 1-19.

Lindsey, P. y Balme, G. (2013). Trophy hunting and lion conservation: a question of governance? Oryx, 47(4), 501-509.

Nshala, R. y Rodgers, W.A. (2007). The evolution and reform of Tanzanian wildlife management. Conservation and Society, 5(2), 232.

Neumann, R.P. (1998). Imposing Wilderness: Struggles over livelihood and nature preservation in Africa. Volume 4. Berkeley: University of California Press.

Ngoitiko, M. y Nelson, F. (2013, octubre 8). What Africa can learn from Tanzanias remarkable Masai lands rights victory. The Guardian. Recuperado de: www.theguardian.com/global-development/ poverty-matters/2013/oct/08/africa-tanzania-masai-land-rights-victory

Niassa Carnivore Project (2013). Niassa Carnivore Project. Recuperado de: niassalion.org/index.php

Norwegian University of Science and Technology. (2013, mayo 23). Serengeti road divides biologists: will a road across the northern tier of Serengeti National Park ruin it? ScienceDaily. Recuperado de: www.sciencedaily.com/releases/2013/05/130523082921.htm

Oates, J. (1999). Myth and Reality in the Rain Forest: How conservation strategies are failing in West Africa. Berkeley: University of California Press.

Observatorio Latinoamericano de Conflictos Ambientales (OLCA). (2014). Santiago. Recuperado de: olca. $\mathrm{cl} /$ oca/chile/region $11 /$ represas $56 . \mathrm{htm}$

Oglethorpe, J.A.E. (ed.). (1999). Tenure and Sustainable Use. Gland: IUCN. 
Onishi, N. (2005, febrero 15). South Koreas "sea women" trap prey and turn tables. The New York Times. Recuperado de: www.nytimes. com/2005/02/15/international/asia/15udo.html?_r=0

Ostrom, E. (1990). Governing the Commons: The evolution of institutions for collective action. Cambridge: Cambridge University Press.

Padulosi, S.; Hunter, D.; Jarvis, A. y Heywood, V. (2011). Underutilized crops and climate change - current status and outlook. En: S. Yadav, B. Redden, J.L. Hatfield y H. Lotze-Campen (eds.). Crop Adaptation to Climate Change, pp. 507-521. Ames, Estados Unidos: Wiley-Blackwell.

Pandey, S. (2008). Linking ecodevelopment and biodiversity conservation at the Great Himalayan National Park, India: lessons learnt. Biodiversity and Conservation, 17, 1543-1571.

Wells, M. (1997). Ecodevelopment planning at Indias Great Himalayan National Park for biodiversity conservation and participatory rural development. Biodiversity and Conservation, 6(9), 1277-1292.

Parr, S.; Dunford, B.; Moran, J.; Williams, B. y Conchuir, R. (2010). BurrenLIFE - farming for conservation in the Burren. En: C. Belair, K. Ichikawa, B.Y.L. Wong y K.J. Mulongoy (eds.). Sustainable Use of Biological Diversity in Socio-Ecological Production Landscapes: Background to the Satoyama Initiative for the Benefit of Biodiversity and Human Well-Being, pp. 142-148, CBD Technical Series No. 52, Montreal: Secretariat of the Convention on Biological Diversity.

Parrotta, J.A. y Trosper, R.L. (eds.). (2012). Traditional Forest-Related Knowledge. Nueva York: Springer.

Pathak Broome, N. y Dash, T. (2012). Recognition and support of ICCAs in India. En: A. Kothari, C. Corrigan, H. Jonas, A. Neumann y H. Shrumm (eds.). Recognizing and Supporting Territories and Areas Conserved by Indigenous Peoples and Local Communities: Global overview and national case studies, pp. 130-2, CBD Technical Series No. 64. Montreal: Secretariat of the Convention on Biological Diversity, ICCA Consortium, Kalpavriksh y Natural Justice.

Perfecto, I.; Vandermeer, J. y Wright, A. (2009). Natures Matrix: Linking agriculture, conservation and food sovereignty. Londres: Earthscan.
Periyar Tiger Reserve. (2012). India Eco Development Project. Thekkadi, India: Periyar Tiger Reserve. Recuperado de: www.periyartigerreserve.org/indian.php

Fondo de Promoción de las Áreas Naturales Protegidas del Perú (PROFONANPE). (2012). Lima. Recuperado de: www.profonanpe.org.pe/index.php/en/projects

Pfeiffer, C. (2009, febrero 7). Mermaids of the deep. Sydney Morning Herald Traveller. 7 February. Recuperado de: www.smh.com.au/travel/activity/surfing-and-diving/mermaids-of-the-deep20090204-7xbg.html

Porter-Bolland, L.; Ellis, E.A.; Guariguata, M.R.; Ruiz-Mallen, I.; Negrete-Yankelevich, S. y Reyes-Garcia, V. (2012). Community managed forests and forest protected areas: an assessment of their conservation effectiveness across the tropics. Forest Ecology and Management, 268 (marzo), 6-17. Doi:10.1016/j.foreco.2011.05.034

Posey, D. (ed.). (1999). Cultural and Spiritual Values of Biodiversity. Nairobi: United Nations Environment Programme y Londres: Intermediate Technology Publications.

Pretty, J. (2002). People, livelihoods and collective action in biodiversity management. En: T. ORiordan y S. Stoll-Kleemann (eds.). Biodiversity, Sustainability, and Human Communities: Protecting beyond the protected, pp. 61-86. Cambridge: Cambridge University Press.

Programa Estado de la Nación. (2006). Duodécimo informe Estado de la Nación en Desarrollo Humano Sostenible/Programa Estado de la Nación. San José, Costa Rica. Recuperado de: www.estadonacion. or.cr/files/biblioteca_virtual/006/info6cap4.pdf

Radachowsky, J.; Ramos, V.H.; McNab, R.; Baur, E.H. y Kazakov, N. (2012). Forest concessions in the Maya Biosphere Reserve, Guatemala: a decade later. Forest Ecology and Management, 268, 18-28. Doi:10.1016/j.foreco.2011.08.043

Redmond, I.; Aldred, T.; Jedamzik, K. y Westwood, M. (2006). Recipes for Survival: Controlling the bushmeat trade. Londres: World Society for the Protection of Animals.

Reid, H. (2001). Contractual national parks and the Makuleke community. Human Ecology, 29(2), 135-155. 
Rijnhout, L.; de Zoysa, U.; Kothari, A. y Healy, H. (2014). Towards a global agenda of sustainability and equity: civil society engagement for the future we want. UNEP Perspectives, 12 (marzo), 1-12. Recuperado de: www.unep.org/post2015/Publications/ TowardsAGlobalAgendaOfSustainabilityAndEqui/ tabid/133352/Default.aspx

Roe, D.; Nelson, F. y Sandbrook, C. (eds.). (2009). Community Management of Natural Resources in Africa: Impacts, experiences and future directions. $\mathrm{Na}-$ tural Resource Issues No. 18. Londres: International Institute for Environment and Development.

Rybanič, R.; Šeffer, J. y Čierna, M. (1999). Economic valuation of benefits from conservation and restoration of floodplain meadows. En: J. Šeffer y V. Stanová (eds.). Morava River Floodplain Meadows - Importance, restoration and management, pp. 147-160. Bratislava: DAPHNE-Institute of Applied Ecology.

Saberwal, V.; Rangarajan, M. y Kothari, A. (2001). People, Parks and Wildlife: Tracts for the times, 14. Nueva Delhi: Orient Longman.

Salm, R.V.; Clark, J.R. y Siirila, E. (2000). Marine and Coastal Protected Areas: A guide for planners and managers. Gland: IUCN.

Sathurusinghe, A.; Seneneyake, S.J.G.N.; Wijesundara, D.S.A. y Wijesekara, G.A.W. (2010). Species management plan for Cinnamomum capparu-coronde Blume. En: B. Marambe y A. Wijesekara (eds.). Conservation and Utilization of Crop Wild Relatives of Sri Lanka, pp. 35-36. Sri Lanka: Department of Agriculture and Ministry of Environment and Natural Resources.

Schippmann, U.; Leaman, D. y Cunningham, A.B. (2006). Cultivation and wild collection of medicinal and aromatic plants under sustainability aspects. En: R.J. Bogers, L.E. Craker y D. Lange (eds.). Medicinal and Aromatic Plants: Agricultural, commercial, ecological, legal, pharmacological and social aspects. Dordrecht, Países Bajos: Springer.

Schliep, R.; Bertzky, M.; Hirschnitz, M. y Stoll- Kleemann, S. (2008). Changing climate in protected areas? Risk perception of climate change by biosphere reserve managers. GAIA, 17(1), 116-124.

Schulte-Herbrüggen, B.; Cowlishaw, G.; Homewood, K. y Rowcliffe, J.M. (2013). The importance of bushmeat in the livelihoods of West African cash-crop farmers living in a faunally-depleted landscape. PloS One, 8(8), e72807.
Shahabuddin, G. (2010). India ecodevelopment project: a fragmented legacy. En: G. Shahabuddin Conservation Crossroads: Science, society and the future of Indias wildlife, pp. 166-186. Delhi: Permanent Black.

Shriar, A. (1999). Resource conservation and rural neglect: an example from Petén, Guatemala. Delaware Review of Latin American Studies, 1(1). Recuperado de: www.udel.edu/LASP/vol1Avrum.html

Skeena Watershed Conservation Coalition. (2014). Skeena Watershed Conservation Coalition, Old Hazelton, British Columbia. skeenawatershed. com

Skeena Wild Conservation Trust (2014). Skeena Wild Conservation Trust. British Columbia: Terrace. Recuperado de: skeenawild.org

Spalding, M.D.; Meliane, I.; Milam, A.; Fitzgerald, C. y Hale, L.Z. (2013). Protecting marine spaces: global targets and changing approaches. Ocean Yearbook, 27, 213-248.

Spence, M. (1999). Dispossessing the Wilderness: Indian removal and the making of the national parks. Nueva York: Oxford University Press.

Spenceley, A. (ed.). (2008). Responsible Tourism: Critical issues for conservation and development. Nueva York: Routledge.

Steenkamp, C. y Uhr, J. (2000). The Makuleke Land Claim: Power relations and community-based natural resource management. Londres: International Institute for Environment and Development.

Stoll-Kleemann, S. y Welp, M. (2008). Participatory and integrated management of biosphere reserves. GAIA, 17, 161-168.

Sustainable Development Knowledge Platform. (2014). Sustainable Development Knowledge Platform. sustainabledevelopment.un.org

Tairo, A. (2014, mayo 13). Tanzania gives go ahead to uranium mining in Selous Game Reserve. eTurboNews. Recuperado de: www.eturbonews. com/45745/tanzania-gives-go-ahead-uranium-mining-selous-game-reserve

Tandon, V. (2002). Getting women to choose: case study on sustainable livelihoods and poverty alleviation. Bishkek, Kyrgyzstan: Mountain Forum E-Consultation for the UNEP/Bishkek Global Mountain Summit, octubre 29 - noviembre 1. 
Tebtebba Foundation. (2008). Indicators Relevant for Indigenous Peoples: A resource book. Tebtebba Foundation. Baguio City, Philippines. Recuperado de: www.tebtebba.org/index.php/content/123-indicators-relevant-for-indigenous-peoples-a-resource-book $\% 20 \% 20$

Technical and Policy Core Group (TPCG) y Kalpavriksh (2005). Securing India's future: final technical report of the National Biodiversity Strategy and Action Plan. Pune, India: Technical and Policy Core Group and Kalpavriksh. Recuperado de: www.kalpavriksh.org/ index.php/conservation-livelihoods1/72-biodiversity-and-wildlife/national-biodiversity-strategy-action-plan/224-nbsap-final-technical-report.html

Terborgh, J. (2004). Requiem for Nature. Washington D.C.: Island Press.

United Nations (UN). (2009). State of the Worlds Indigenous Peoples. Nueva York: United Nations.

United Nations Conference on Sustainable Development (UNCSD). (2012). The Future We Want, A/ Conf.216/L.1. Nueva York: United Nations. Recuperado de: www.uncsd2012.org/content/documents/774futurewewant_english.pdf

United Nations University Institute of Advanced Studies Operating Unit Ishikawa/Kanazawa (UNU-IAS OUIK). (2011). Biological and Cultural Diversity in Coastal Communities: Exploring the potential of satoumi for implementing the ecosystem approach in the Japanese Archipelago, Technical Series No. 61. Montreal: Secretariat of the Convention on Biological Diversity.

United States Fish y Wildlife Service. (2014). Refuge-Specific Hunting and Sport Fishing Regulations. National Wildlife Refuge System. Recuperado de: www.fws.gov/refuges/hunting/huntfishregs.html

Unnikrishnan, P.M. y Suneetha, M.S. (2012). Biodiversity, traditional knowledge and community health: strengthening linkages, UNU-IAS Policy Report. Yokohama, Japón: United Nations University Institute of Advanced Studies. Recuperado de: www. ias.unu.edu/resource_centre/Biodiversity $\% 20$ Traditional\%20Knowledge\%20and\%20 Community\%20Health_final.pdf

Van Oudenhoven, F.; Mijatovic, D. y Eyzaguirre, P. (2011). Social-ecological indicators of resilience in agrarian and natural landscapes. Management of Environmental Quality: An International Journal, 22(2), 154-173.
Van Vliet, N.; Nasi, R.; Abernethy, K.; Fargeot, C.; Kumpel, N.F.; Obiang, A.N. y Ringuet, S. (2012). The role of wildlife for food security in Central Africa: a threat to biodiversity? En: C. de Wasseige, P. de Marcken, N. Bayol, F. Hiol-Hiol, P. Mayaux, B. Desclee, R. Nasi, A. Billand, P. Defourny y R. Ebaa Atyi (eds.). The Forests of the Congo Basin: State of the forest 2010, pp. 123-135. Luxembourgo: Publications Office of the European Union. Doi: $10.2788 / 47210$

Vasundhara and Kalpavriksh. (2012). A National Report on Community Forest Rights under Forest Rights Act: Status and issues. An output of the Community Forest Rights Learning and Advocacy Process. Delhi y Pune: Vasundhara, Bhubaneshwar y Kalpavriksh.

Vaughan, C.; McCoy, M.; Fallas, J.; Chaves, H.; Barboza, G.; Wong, G.; Rau, J.; Carranza, M. y Carbonell, M. (1996). Management and Development for Palo Verde National Park and Lomas Barbudal Biological Reserve. Heredia, Costa Rica: National University of Costa Rica.

Vijayan, V.S. (1991). Keoladeo National Park Ecology Study: 1980-90. Final report. Bombay: Bombay Natural History Society.

Wahren, C.-H.; Papst, W.A. y Williams, R.J. (1994). Long-term vegetation change in relation to cattle grazing in subalpine grassland and heathland on the Bogong High Plains: an analysis of vegetation records from 1945 to 1994. Australian Journal of Botany, 42, 607-639.

Wani, M. y Kothari, A. (2007). Protected areas and human rights in India - the impact of the official conservation model on local communities. Policy Matters, 15, 100-114.

Washington Post. (2013, mayo 27). In Brazil, Amazonian Indians protest hydroelectric dam. Washington Post, Recuperado de: www.washingtonpost.com/ world/in-brazil-amazonian-indians-protest-hydroelectric-dam/2013/06/10/f90539b6-cee511e2-8845-d970ccb04497_gallery.html\#photo=1

Wells, M.; Brandon, K. y Hannah, L. (1992). People and Parks: Linking protected area management with local communities. Washington D.C.: The World Bank, WWF y US Agency for International Development.

Guggenheim, S.; Khan, A.; Wardojo, W. y Jepson, P. (1999). Investing in Biodiversity: A review of Indonesia's integrated conservation and development projects. Washington D.C.: The World Bank. 
Dest, P.; Igoe, J. y Brockington, D. (2006). Parks and peoples: the social impact of protected areas. Annual Review of Anthropology, 35, 251-277.

Western, D. y Gichohi, H. (1993). Segregation effects and the impoverishment of savanna parks: the case for ecosystem viability analysis. African Journal of Ecology, 31(4), 269-281.

Wieting, R. (2004). Sustainable Land Use in European Protected Areas. Bruselas: IUCN Regional Office for Europe.

Wikipedia. (2014). Niassa Reserve. Recuperado de: en.wikipedia.org/wiki/Niassa_Reserve

Wildlife Institute of India (WII). (1999). An Ecological Study of the Conservation of Biodiversity and Biotic Pressures in the Great Himalayan National Park Conservation Area: An ecodevelopment approach. Volumes 1-6, Reporte final, Forestry Research Education and Extension Project - Great Himalayan National Park. Dehradun, India: Wildlife Institute of India.

Williams, R.J. (1990). Cattle grazing within subalpine heathland and grassland communities on the Bogong High Plains: disturbance, regeneration and the shrub-grass balance. Proceedings of the Ecological Society of Australia, 16, 255-265.

Wittmer, H.U.; Mark Elbroch, L. y Marshall, A.J. (2013). Good intentions gone wrong: did conservation management threaten endangered huemul deer Hippocamelus bisulcus in the future Patagonia National Park? Oryx, 47(3), 393-402. Doi: $10.1017 /$ S0030605312000531

World Resources Institute (WRI), International Union for Conservation of Nature (IUCN) y United Nations Environment Programme (UNEP). (1992). Global Biodiversity Strategy: Guidelines for action to save, study, and use Earth's biotic wealth sustainably and equitably. Gland: WRI, IUCN y UNEP.

World Wildlife Fund (WWF). (2014). PADDDtracker: Tracking protected area downgrading, downsizing, and degazettement. Recuperado de: www. PADDDtracker.org
Zinn, C. y Vidal, J. (1999, enero 14). How prawn cocktails and tourists are taking the life out of the Great Barrier Reef. The Guardian. Recuperado de: www.theguardian.com/world/1999/jan/14/ johnvidal 
Este texto se tomó de Protected Area Governance and Management, editado por Graeme L. Worboys, Michael Lockwood, Ashish Kothari, Sue Feary e Ian Pulsford, publicado en 2019 por ANU Press, Universidad Nacional de Australia, Canberra, Australia.

La reproducción de esta publicación de ANU Press con fines educativos u otros fines no comerciales está autorizada sin el permiso previo por escrito del titular de los derechos de autor, siempre y cuando se indique claramente la fuente. La reproducción de esta publicación para su reventa u otros fines comerciales está prohibida sin el permiso previo por escrito del titular de los derechos de autor. 